Türkiye Jeoloji Bülteni
Geological Bulletin of Turkey
$60(2017) 145-168$
http://tjb.jmo.org.tr

\title{
Marmara ve Karadeniz Kıyılarındaki Güncel Sedimanlar İçinde Antroposen'in Varlığına Ait Yeni Bulgular
}

\author{
New Findings of Existence Anthropocene in Recent Sediments at Marmara and Black Sea Coast
}

\author{
Akın Alak*, Ökmen Sümer
}

Dokuz Eylül Üniversitesi, Jeoloji Mühendisliği Bölümü, Tınaztepe Kampüsü, Buca-İzmir

Geliş/Received : 16.05.2016 • Düzeltilmiş Metin Geliş/Revised Manuscript Received : 10.10.2016 • Kabul/Accepted : 14.10.2016 • Bask1/Printed : 01.04 .2017 Araştırma Makalesi/Research Article Türkije Jeol. Bül. / Geol. Bull. Turkey

Öz: Sanayileşme, fosil yakıtların kullanımı, kontrolsüz tarım ve buna benzer insan faaliyetleri her geçen gün artmakta, bu faaliyetler sonucunda doğada bir takım değişiklikler ve antropojenik kirlikler meydana gelmektedir. Bu çalışma kapsamında, Marmara'da İzmit Körfezi (IZC-01), Karadeniz'de Sürmene (SC-01) ve Hopa (HC-01) kıyılarından alınan karot örnekleri, antropojenik kirliliğin varlığının araştırılması adına, litolojik, sedimantolojik, paleontolojik ve jeokimyasal açıdan incelenmiş, her bir karottan 15 numune olmak üzere toplamda 45 örneğin $\mathrm{As}, \mathrm{Ba}, \mathrm{Pb}, \mathrm{Cd}, \mathrm{Cr}$, $\mathrm{Ni}$, Ti ve $\mathrm{Zn}$ gibi ağır metal konsantrasyonları değerlendirilmiştir. Karot örneklerindeki $\mathrm{As}, \mathrm{Ba}, \mathrm{Pb}, \mathrm{Cr}$, Ni, ve $\mathrm{Zn}$ elementlerinin analiz sonuçları kullanılarak hesaplanan PLI (Kirlilik Yükü İndeksi; Pollution Load Index) kirlilik değerleri, İzmit Körfezi için 3.255, Sürmene ve Hopa'da sırasıly 2.195 ve 1.706 olarak ölçülmüştür. Hesaplanan PLI değerleri sonuçları, İzmit Körfezi’nin kabul edilir kirlilik seviyesinin üzerinde, Sürmene ve Hopa'nın ise kirli olmalarına rağmen nispeten daha az kirli olduğunu göstermektedir. Bunun yanında EF (Zenginleşme Faktörü; Enrichment Factor) değerleri, İzmit Körfezi'nde As, Ni ve Cr elementlerinin belirgin bir zenginleşme, $\mathrm{Pb}$ ve $\mathrm{Zn}$ elementlerinin ise orta derecede zenginleştiğine işaret eder. Sürmene ve Hopa lokasyonlarında ise As, Ba ve Cr gibi elementler yetersiz zenginleşme gösterirken, $\mathrm{Ni}, \mathrm{Pb}$ ve $\mathrm{Zn}$ elementlerde belirgin bir zenginleşme olduğu gözlenmiştir. Marmara karotu özelinde kirliğe bağlı gelişmiş jips kristalizasyonu da dikkat çekicidir. Karotlardaki paleontolojik bulguların bolluğu ve çeşitliliği de, kirlilik oranlarıyla uyumlu şekilde azalıp artar. Her 3 karotta da derine gidildikçe $\mathrm{Pb}, \mathrm{Zn}, \mathrm{Cr}$ ve As gibi elementlerin konsatrasyonlarında bir azalma olduğu görülmüş ve bu azalmaların anomali

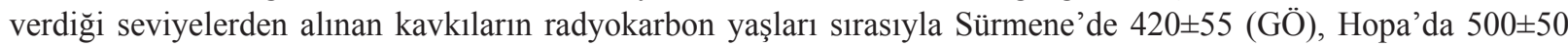
(GÖ) olarak elde edilmiştir. Ayrıca bölgede yapılan diğer sedimantasyon hızına dayanan çalışmaların sonuçları ile bu yaşlar uyumluluk gösterir. Belirlenen bu yaş aralıkları Antroposen'in başlangıcı ile ilgili literatürdeki görüşler ile karşılaş̧ırılmış ve değişimlerin bariz bir şekilde gözlendiği seviyeler, olası Antroposen sınırı olarak yorumlanmıştır. Anahtar Kelimeler: Ağır metal analizi, Antropojenik kirlilik, Antroposen, Karadeniz, Marmara.

Abstract: With each passing day, industrialization, the use of fossil fuels, uncontrolled agriculture and similar human activities are increasing. As a results of these activities, the nature is impacted by a number of changes and anthropogenic pollution. In this study, drilling core samples from the Izmit Bay (IZC-01) in the Sea of Marmara, Surmene (SC-01) and Hopa (HC-01) coasts in the Black Sea have been investigated with lithological, sedimentological, paleontological and geochemical perspectives. The concentrations of heavy metals $a s B a, A s, P b$, $\mathrm{Cd}, \mathrm{Cr}, \mathrm{Ni}$, Ti and $\mathrm{Zn}$ were considered from total of 45 samples which are covering 15 samples from each three cores. PLI (Pollution load index) values are calculated by using the results of $\mathrm{As}, \mathrm{Ba}, \mathrm{Pb}, \mathrm{Cr}, \mathrm{Ni}$, and $\mathrm{Zn}$ elements, stand out 3.255 for the Gulf of Izmit, 2,195 and 1,706 for Surmene and Hopa in respectively. PLI values indicate accepted level of pollution above for the Gulf of Izmit and despite being dirty Sürmene and Hopa relatively less polluted. In addition, EF values indicate a significant enrichment of the $\mathrm{As}, \mathrm{Ni}$ and $\mathrm{Cr}$ and moderate enrichment of $\mathrm{Pb}$ and $\mathrm{Zn}$ elements at Izmit Gulf. In locations Hopa and Sürmene; As, Ba and Cr elements showing insufficient enrichment

*Yazısma / Correspondence: akin.alak@yandex.com

(C) 2017 JMO Her hakkı saklıdır/All rights reserved 
and $\mathrm{Ni}, \mathrm{Pb}$ and $\mathrm{Zn}$ was observed a significant enrichment. Besides, pollution related gypsum crystallization is also remarkable for Maramara core. The abundance and diversity of paleontological records in the cores are also compatible in line with the decreasing and increasing rate of pollution. Towards the deepest part of the all 3 cores, a reduction in the concentrations of elements such as $\mathrm{Pb}, \mathrm{Zn}, \mathrm{Cr}$ and $\mathrm{As}$ is seen. Radiocarbon dates obtained from the shells of these reduction levels are mesured in Sürmene $420 \pm 55$ (BP) and Hopa 500 50 (BP). In addition, results of the other previous studies based on sedimentation rate and these ages are compatible. These specified age ranges were compared with opinions in the literature which are related to the beginning of Anthropocene and because of the overlaping, these clearly observed levels have been interpreted as the limit of the possible Anthropocene time.

Key Words: Anthropocene, anthropogenic pollution, Black Sea, Heavy metal analysis, Sea of Marmara

\section{GİRIŞ}

İnsan faaliyetleri her geçen gün giderek artmakta ve bu faaliyetler, doğa koşullarını olumlu ya da olumsuz dahaçok da olumsuzyönde etkilemektedir. Bu etkiler, insanı doğada yaşayan sıradan bir türün ötesine taşıyarak, küresel çapta, doğanın kendi işleyişi dışında belirleyici gücü olan, katalizör görevinde biyolojik, kimyasal ve jeolojik bir aktör haline getirmiştir (Crutzen ve Stoermer, 2000; Andersson vd. 2005; Crossland vd. 2005; Crutzen, 2006). İnsanın doğal ortam üzerindeki etkisi, makineleşme ve bunun sonucu olan sanayileşme ile ivmelenmiş, nüfus artışı ile birlikte bu etki yeryüzünün büyük bir bölümüne yayılmıştır. Literatürde, insanın doğa üzerine etkisinin ciddi bir şekilde kanıtlarıyla ilk araştırıldığı çalışma Marsh (1864) ile başlamaktadır. Diğer yandan insanın doğa üzerinde aslında kirlilik bazında yarattığ 1 bu etkileri, terminolojik olarak ilk kez 1922 yıllında Alexei Petrovich Pavlov Antropojenik kirlenme/etkiler olarak tanımlamıştır (Bampton, 1999). İnsanoğlunun ekosistemlere etkisiyle oluşmuş/oluşan bu kirlenmelerin sonucunda ise antropojenik biyomlar ortaya çıkmaktadır (Ellis ve Ramankutty, 2008). Bu antropojenik etkilerin, jeolojik kayaçlar veya olaylarda gözlenebilir ve ölçülebilir olmasından yola çıkarak, Crutzen ve Stoermer (2000) içinde bulunduğumuz jeolojik seri olan Holosen'in zamansal olarak ayrilması ve Antroposen şeklinde yeni bir jeolojik seriye girilmesi gerektiğini savunmuştur. Son yıllarda özellikle bu alanda yapılan bilimsel çalışmalarla,
Antroposen'in varlığg ile ilgili bir fikir birliğine gidilse de, başlangıcı ile ilgili farklı görüşler olduğu görülmektedir. Genel yaklaşımda 3 ana görüş bulunur; (1) Antroposen, kontrolsüz tarımın başlaması ve verimsiz arazi kullanımının artması gibi erken insan etkileri sonucunda, karalarda ve denizlerdeki biyolojik habitatın değişimi ve buna bağlı $\mathrm{CO}_{2}$ seviyesinin artmasının tetiklendiği dönemlerden itibaren, yaklaş1k 8000-3000 yıl önce başlamış olmalıdır (Ruddiman, 2003; Certini ve Scalenghe, 2011; Ellis, 2011; Wilkinson vd. 2014).

(2) Fosil yakıtların kullanılmasının yaygınlaşması ve özellikle 18.yüzyıl sonlarında gerçekleşen sanayi devrimi ile artarak tetiklenmiş etkilerin, gözlenir bir şekilde doğa üzerindeki etkisinin ortaya çıkmasıyla birlikte son 200 - 500 yıl içinde başlamış olmalıdır (Crutzen ve Stoermer, 2000; Crutzen, 2002; Davis, 2011; Fischer-Kowalski vd. 2014). (3) Özellikle 2. Dünya savaşı sonrasında, insan popülasyonun ve global ekonomik gelişmelerin devasa boyutlardaki artışı ile, buna ek olarak antropojenik sinyallerin ilk atom bombas ile radyoaktif bir kirlenmeye sebebiyet verdiği ve daha ölçülebilir hale geldiğinden yola çıkarak, Antroposen - Holosen sinırı 20. yy ortalarına karşılık gelmelidir (Steffen vd. 2007; Wolfe vd. 2014; Zalasiewicz vd. 2015; Waters vd. 2016). Özellikle bu jeolojik zaman sınırının araştırılması dışında, Dünya ve Türkiye özelinde antropojenik etkilerin incelendiği ve ölçüldüğü çalışmalar da oldukça yaygındır (örnğ. Balkıs vd. 2012; Kaska vd., 2010; Şener vd., 2013; Gürbüz ve Gürer, 
2008; Yatkın ve Bayram, 2008; Aslan-Yılmaz vd. 2004; Güler vd. 2012; Yang vd., 2015; Eichler vd. 2014; Moore vd. 2011; Bhuiyan vd. 2010; Essien vd. 2009; Ray vd. 2006; Bermejo vd. 2003; Owen vd. 2000; Palanques ve Diaz, 1994).

Ağır metaller toksik etkileri ve birikim özellikleriyle, çevre için önemli ölçüde bir kirlilik oluşturduğu bilindiği için (Omgbu ve Kokogbo, 1993), Türkiye genelinde, özellikle antropojenik etkilerle ile ilgili çalışmalar daha çok ağır metal kirliliğinin ölçülmesi ile araştırılmaktadır. Benzer yöntemlerle, Ergin vd. (1991) Haliç ve İzmit Körfezine ait 57 adet yüzey sediman örneğinde; $\mathrm{Fe}, \mathrm{Mn}, \mathrm{Cr}, \mathrm{Ni}, \mathrm{Co}, \mathrm{Zn}, \mathrm{Pb}$ ve $\mathrm{Cu}$ gibi ağır metallerin konsantrasyonun araştırmış, Haliçteki konsantrasyonun İzmit Körfezine nazaran daha yoğun olduğunu belirtmiş. Yaşar vd. (2001), İzmit Körfezi'nden aldıkları 24 örnekten yaptıkları analizlerde sedimanlarının toplam organik karbon ve sülfür ile gelişen $\mathrm{Ag}, \mathrm{As}, \mathrm{Cd}, \mathrm{Cr}, \mathrm{Co}, \mathrm{Cu}$, $\mathrm{Hg}, \mathrm{Mo}, \mathrm{P}, \mathrm{Pb}, \mathrm{Sb}, \mathrm{Ti}, \mathrm{V}$, ve $\mathrm{Zn}$ gibi ağır metal yoğunluklarında artış olduğunu belirtmekte ve bu artışın bölgedeki sanayileşme ile ilişkili olduğunu savunmaktadır. Aynı şekilde Aksu vd. (1998) ise İzmir Körfezi yüzey sedimanlarında 84 örnekten 42 elementin yoğunluklarını değerlendirmiş, toplam organik karbon ve sülfür ile bağlantılı olarak gelişen $\mathrm{Ag}, \mathrm{As}, \mathrm{Cd}, \mathrm{Cr}, \mathrm{Cu}, \mathrm{Hg}, \mathrm{Mo}, \mathrm{P}$, $\mathrm{Pb}, \mathrm{Sb}, \mathrm{Sn}, \mathrm{V}$, ve $\mathrm{Zn}$ gibi ağır metallerin belirgin bir zenginleşme gösterdiğini belirtmiş, bu kirlenmenin 1976'dan 1990 yıllarına kadar körfezde yapılan kirli sedimanlarının tarama ve döküm işlemleri sonucunda oluştuğu yorumunu yapmıştır. Balkıs vd. (2012) İstanbul Boğazı'nın farklı lokasyonlarından aldıkları 5 örneğin $\mathrm{Pb}$, $\mathrm{Cd}$ ve $\mathrm{Hg}$ konsantrasyonlarını değerlendirmiş ve Kirlilik Faktörü açısından; Hg için herhangi bir antropojenik kirlenme olmadığını, $\mathrm{Pb}$ ve $\mathrm{Cd}$ açısından ise orta seviye bir kirlenmenin var olduğunu belirtmişlerdir. Evans vd. (1989) ise diğer çalışmalardan farklı biçimde, kuzeydoğu Marmara' daki iki karotta, ağır metal kirliliklerinin derine doğru değişimlerini incelemiş ve antropojenik kirliliğin son 1000 y1l içinde arttığını belirtmiştir. Fakat araştırıcılar doğal olarak, Crutzen ve Stoermer (2000) tarafindan Antroposen kavramının ortaya atıldığ 1 dönemden önceki bir dönemde yaptıkları çalışmalarında, bu zaman diliminin ayrımı ile ilgili tartışmalara değinememiştir.

Yukarıda da belirtildiği gibi, Türkiye özelinde antropojenik kirlenmenin varlığ 1 yoğun bir şekilde araştırılsa ve hatta varlığı desteklenmiş olsa da, bu kirlenmenin başlangıcı ve/veya varsa jeolojik zaman içindeki değişimleri, kontrollü bir biçimde yöntemsel olarak katmanlar içinde jeolojik olarak eski dönemlere gidilerek Marmara'da Evans vd. (1989), Ege Denizi'nde ise Atalar vd. (2013) dışında hiç araştırılmamıştır. Fakat bu çalışmalarda da, kirlenmenin başlangıcına ait bir kronolojik yaklaşım mutlak yaş verileriyle tartışılmamıştır. Bu çalışma kapsamında, İzmit Körfezi (Marmara Denizi), Trabzon ili Sürmene ilçesi ve Artvin ili Hopa ilçesi kıyılarından (Karadeniz) alınan karot örneklerindeki ağır metal bulgularının, sedimanlardaki derinliğe bağ $1_{1}$ değişimi incelenerek, bu değiş̧imlerin günümüzden ne kadar süre önce başladığı ve zamana bağl1 değişim miktarları, Antroposen'in başlangıcının araştırılmasına yönelik ilk kez incelenmiştir. Elde edilen ağır metal konsantrasyonlarının birbirlerine göre benzerlikleri ve farklılıkları, örneklerin alındığ1 lokasyonlara göre irdelenecek, daha önce dünyadaki farklıbölgelerde yapılmış çalışmalardan elde edilen değerler ile karşılaştırılacaktır. Karotlardaki metal konsantrasyonlarının değişim gösterdiği derinliklerden alınan radyometrik yaş verileri $\left({ }^{14} \mathrm{C}\right)$ ile, antropojenik etkilerin başlangıcına dair kronolojik bir yaklaşım sağlanacaktır. Ayrıca, her bir lokasyon için, literatürdeki veriler kullanılarak olası sedimantasyon hılarından yola çıkılarak yaklaşık yaş değerleri hesaplanmış ve saptanan ağır metal değişimlerinin hangi tarih aralıklarında gerçekleştiği, radyometrik yaş verileri de harmanlanarak yorumlanmıştır. Örneklerin analizinden elde edilen bulgular 
ile, hesaplanan ve global ölçekte kullanılan antropojenik kirlenme ile ilgili çalışmalarda sıklıkla kullanılan Kirlilik yük indeksi (PLI; Pollution Load Index) ve Zenginleşme Faktörü (EF; Enrichment Factor) değerleri hesaplanarak, lokasyonlardaki kirlenmenin küresel ölçekte diğer bölgelere göre durumu da irdelenmiştir. Son olarak bu çalışma kapsamında elde edilen tüm veriler 1şığında, Antroposen'in başlangıcına yönelik jeolojik bir ilişkilendirilmenin mümkün olup olmadı̆̆ 1 tartışılacaktır.

\section{MATERYAL VE METOD}

Antropojenik etkilerin araştırılması için literatürde birçok değişik yöntem kullanılmaktadır. Bu etkiler antropojenik anomaliler şeklinde tanımlanmakta ve mekanik, biyolojik, kimyasal olarak 3 ana işlev altında değerlendirilmektedir (Galuszka vd. 2014) (Şekil 1). Özellikle sedimanter kayalar içindeki antropojenik etkilerin araştırılmasında kullanılan en önemli yöntemlerden biri ise jeokimyasal anomalilerin varlığının araştırılmasıdır. $\mathrm{Bu}$ çalışma kapsamında da, benzer şekilde güncel deniz sedimanlarının içindeki jeokimyasal anomaliler değerlendirilmiştir.

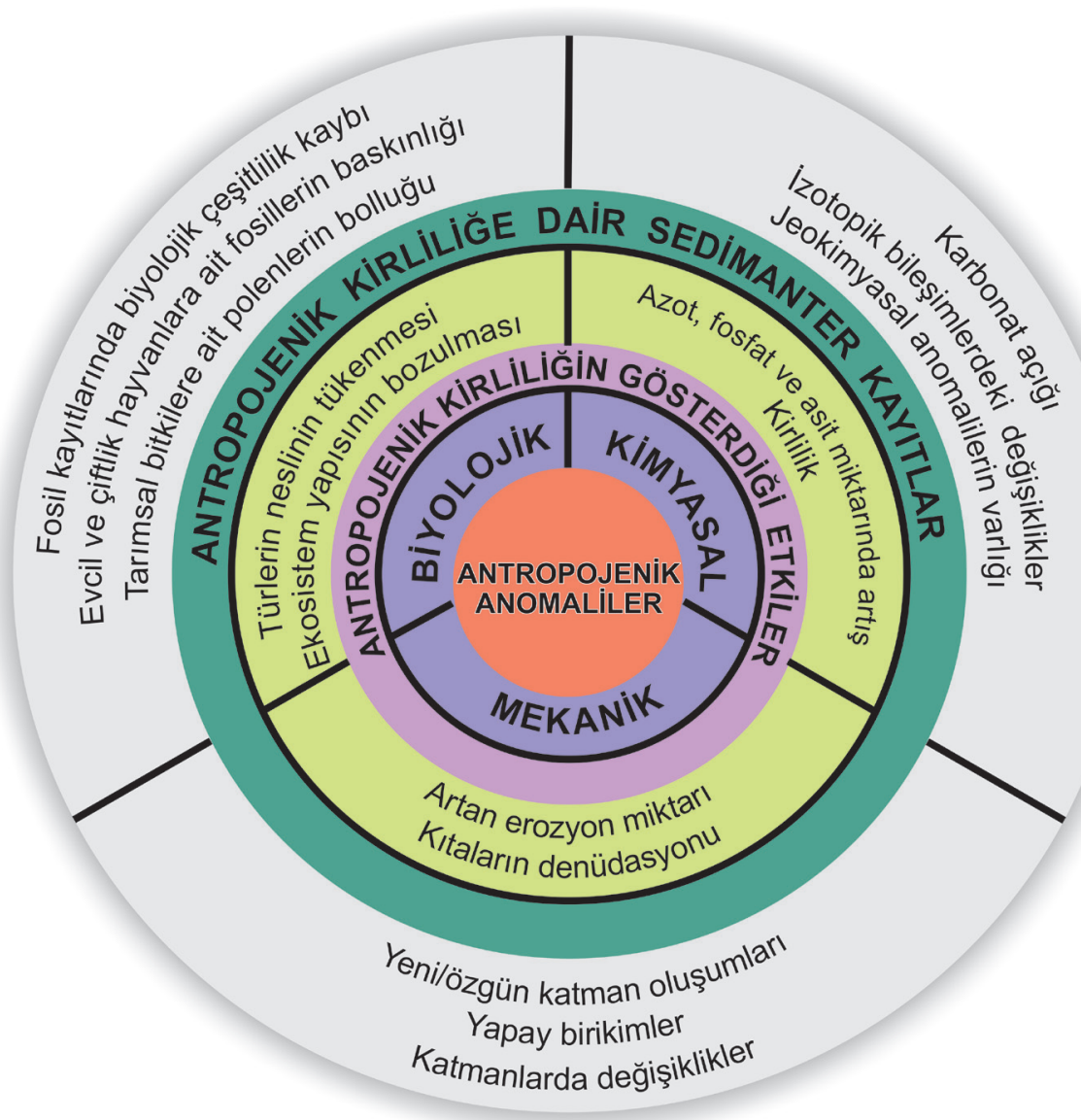

Şekil 1. İnsan kaynaklı antropojenik değişikliklerin olası etkileri ve sedimanlarda gözlenen olası kayıt türleri (Glauszka vd. 2014'den yeniden düzenlenmiştir).

Figure 1. Types of human-induced anthropogenic changes and their possible effects on sedimentary record (modified from Glauszka et al., 2014). 


\section{Örneklerin Temini ve Yer Seçimi}

$\mathrm{Bu}$ çalışma kapsamında Marmara ve Karadeniz kıyılarındaki üç farklı bölgenin deniz tabanından alınan, güncel sedimanlardan oluşan ve farklı boylarda karot örnekleri kullanmıştır. Karot örnekleri, İzmit Körfezi, Trabzon ili Sürmene ilçesi ve Artvin ili Hopa ilçesi kıyılarından alınmıştır (Şekil 2). Alınan karotların boyları Marmara, Sürmene ve Hopa lokasyonları için sirası ile 2 metre, 1,5 metre ve 1 metredir. Dokuz Eylül Üniversitesi'ne ait R.V.K. Piri Reis araştırma gemisi tarafindan gravity core yöntemi kullanılarak alınan karotlardan; İzmit Körfezinin güney kıyısına yakın olan örnek, kıyı çizgisine 110 metre uzaklıkta olup tortul su ara yüzeyi seviyesi 10 metredir (Çizelge 1). Bu bölge ve civarında yerleşim alanları, endüstriyel ve liman faaliyetleri çok aktiftir. Ayrıca uydu görüntülerinden ve topoğrafik haritalardan elde edilen bilgiler 1şı̆̆ında bölgede körfezi besleyen birçok akarsuyun mevcut olduğu da görülmektedir. Diğer bir karot lokasyonu ise Trabzon iline ait Sürmene ilçesi kıyılarıdır. Manahoz Çayının Karadeniz’e döküldüğü bölgeye yakın olan örnekleme alanının güncel kıyı çizgisine uzaklığı 330 metre ve tortul su ara yüzeyi derinliği ise 44 metredir. Bölge civarında ise başta Sürmene ilçesi olmak üzere birçok yerleşim birimi bulunmaktadır. Ayrıca bölgede tarımsal ve endüstriyel faaliyetler de sürdürülmektedir. $\mathrm{Bu}$ çalışma için kullanılan son örnek lokasyonu ise, Artvin ilinin Hopa ilçesi kıyı açığında olup, alan Hopa Deresinin Karadeniz'e döküldüğü denizel akarsu deltası içinde yer almaktadır. Bu lokasyonun güncel kıyı çizgisine uzaklığ 440 metre, tortul su ara yüzeyi derinliği ise 40 metredir (Çizelge 1). Alınan karot örneklerinin yer seçiminde, nüfus, tarımsal ve endüstriyel faaliyetlerin yoğunluğu dikkate alınmıştır. Ayrıca örneklerin alındığı lokasyonların güncel akarsuların denize döküldüğü deltaların üzerinde olması nedeniyle, bölgedeki antropojenik etkilerin taşınarak toplanması açısından önemlidir. Bahsedilen kriterlerin dişında örneklerin yer seçiminde rol alan bir diğer parametre ise bölgelerin coğrafik durumlarıdır. İzmit Körfezi'nin bir iç denizde yer alması ve Marmara Denizi'nin en dingin su altı akıntıları içinde bulunması, bölgede endüstriyel (petrokimya, demir çelik sanayi vb.) faaliyetlerin yoğunluğu, Sürmene ve Hopa ilçesine oranla çok daha fazladır. Bu bağlamda, Marmara ve Karadeniz içinde bulunan ve birbirinden gerek coğrafik gerekse antropojenik olarak farklı seviyelerde olduğu düşünülen bu lokasyonlardaki etkilerin birbirleriyle karşılaştırılarak test edilmesi amaçlanmıştır.

Çizelge 1.Karadeniz ve Marmara'dan alınan karotların detay bilgileri.

Table 1. Detailed description of the cores from the Black Sea and the Marmara Sea.

\begin{tabular}{ccccccc}
\hline Lokasyon & $\begin{array}{c}\text { Karot } \\
\text { kodu }\end{array}$ & $\begin{array}{c}\text { Su derinliği } \\
(\mathbf{m})\end{array}$ & $\begin{array}{c}\text { Kıyı çizgisine } \\
\text { uzaklığı }(\mathbf{m})\end{array}$ & $\begin{array}{c}\text { Karot Boyu } \\
(\mathbf{c m})\end{array}$ & Enlem & Boylam \\
\hline Artvin/Hopa & HC-01 & 21 & 440 & 100 & $0701594 \mathrm{D}$ & $4584951 \mathrm{~K}$ \\
Trabzon/Sürmene & SC-01 & 45 & 330 & 150 & $0593770 \mathrm{D}$ & $4531950 \mathrm{~K}$ \\
İzmit/Başiskele & IZC-01 & 11 & 110 & 200 & $0744815 \mathrm{D}$ & $4511572 \mathrm{~K}$ \\
\hline
\end{tabular}




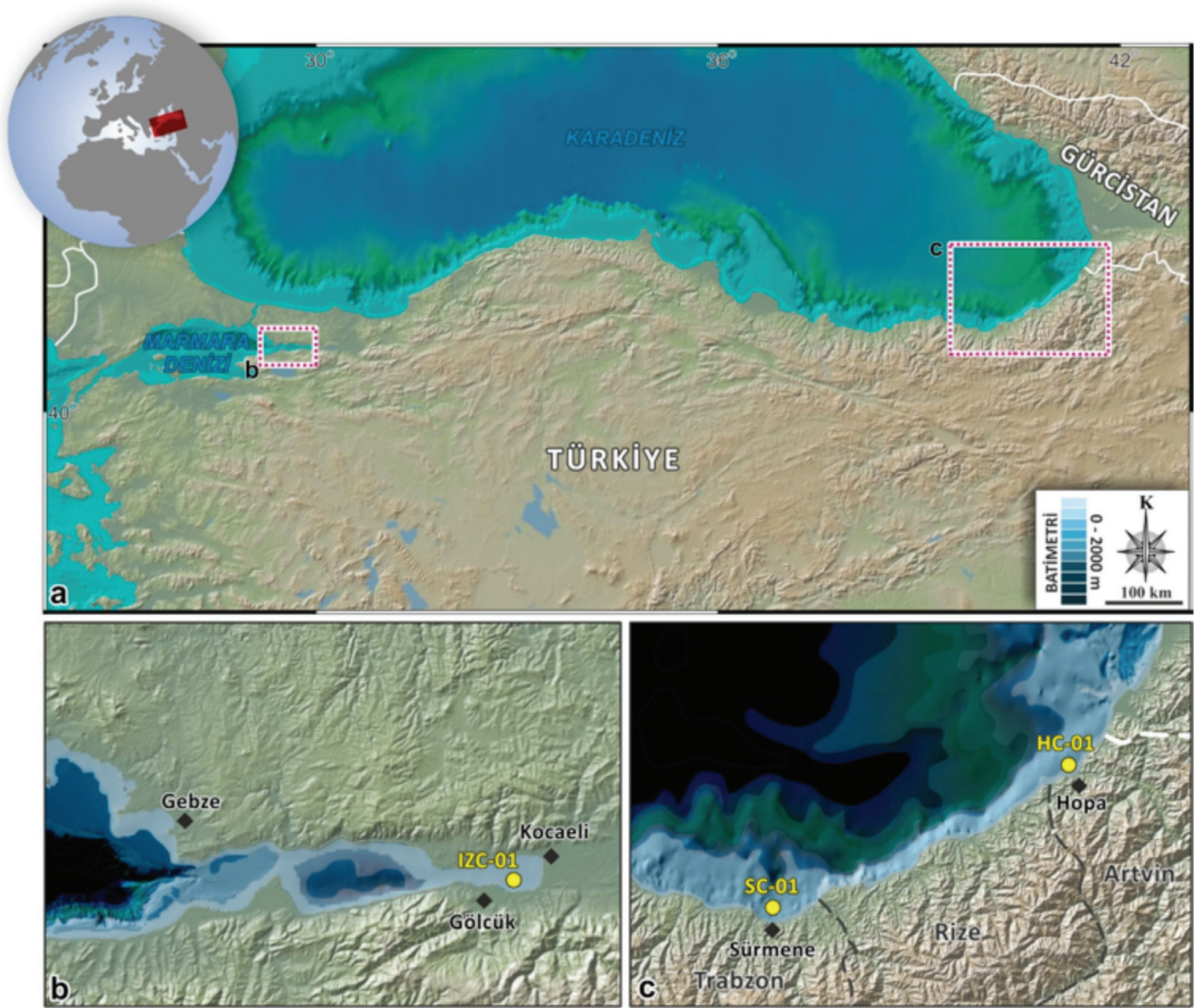

Şekil 2. Marmara ve Karadeniz kıyılarından alınan karotlara ait yer bulduru haritası (Sayısal haritalar Marine Geocience Data System (MGDS) "http://www.marine-geo.org/" veri tabanı üzerinden, batimetrik veriler ise Marmara için Le Surô̂t gemisinin 2000 yılı çalışmalarındaki verileri kullanan Demirbağ vd. 2003'den ve Karadeniz için Hall, 2002'den alınmıştır).

Figure 2. Location map of the cores taken from Marmara and Black Sea (digital elevation maps are taken from Marine Geocience Data System "http://www.marine-geo.org/ database, bathymetric data modified after Demirbağ et al. 2003 who was using data from the vessel Le Suroit in 2000 at Sea of Marmara and Hall, 2002 for Blacksea).

\section{Örneklerin Analiz Aşamaları}

Örnekler, Antroposen'in başlangıcına yönelik farklı görüşler bulunduğundan dolayı, karotların bulunduğu lokasyonlara ait olası sedimantasyon hızları göz önüne alınarak ve günümüzden yaklaşık
1000 yılöncesine denk gelen seviye düşünülerek, su tortul ara yüzeyindeki sedimandan başlamak üzere Hopa ve Sürmene karotlarında önce $3 \mathrm{~cm}$, İzmit karotunda ise önce $4 \mathrm{~cm}$, sonrasında derine doğru eşit aralıklarla kesilerek bölümlere ayrılmıştır. 
$\mathrm{Bu}$ sayede örnekler içerisinde, stratigrafik olarak daha yaşlı olan bölümlerden günümüze gerçekleşmiş olan antropojenik değişimlerinin saptanması amaçlanmıştır. Çalışmada kirlilik artışını araştırmak için, literatürde (örn: Palanques ve Diaz, 1994; Owen ve Sandhu, 2000; Birch vd. 2001; Loska ve Wiechuła, 2003; Essien vd. 2009; Yang vd. 2016'de olduğu gibi) yaygın bir şekilde kullanılan As, Ba, Sn, Pb, Cd, Cr, Ni, Ti ve $\mathrm{Zn}$ elementleri seçilmiştir. Yüksek yoğunluğa sahip ve düşük konsantrasyonlarda bile toksik veya zehirleyici olarak tanımlanan (Kahvecioğlu vd. 2003) bu ağır metallerin genelde insan faaliyetleri ile doğaya salındığı bilindiği için (Sağlam ve Cihangir, 1995), belirlenen ağır metallerin konsantrasyonları değerlendirerek Antropojenik değişimler incelenmiştir.

Alınan karotlar Dokuz Eylül Üniversitesi Mühendislik Fakültesi Örnek Hazırlama Laboratuvarında kesilerek açılmış, öncelikle litolojik, paleontolojik, stratigrafik ve sedimantolojik özellikleri loglanarak, sonrasında belirtilen aralıklarda ayrılan parçalardan, numuneler jeokimyasal analizi için tane boyutu yaklaşık $150 \mu \mathrm{m}$ olacak şekilde ögütülmüştür. Daha sonra örnekler MTA (Maden Tetkik Arama) Genel Müdürlüğü Jeokimya Laboratuvarında; As, $\mathrm{Ba}, \mathrm{Sn}, \mathrm{Pb}, \mathrm{Cd}, \mathrm{Cr}, \mathrm{Ni}$, Ti ve $\mathrm{Zn}$ elementleri için 3'lü asit çözme yöntemi ile 1:2:2 oranında derişik $\mathrm{HClO}_{4}+\mathrm{HCl}+\mathrm{HNO}_{3}$ ile $300^{\circ} \mathrm{C}$ 1sitici tablada 2 saat bekletildikten sonra, derişik 3:1 oranında $\mathrm{HCl}+\mathrm{HNO}_{3}$ çözücüde $300{ }^{\circ} \mathrm{C}$ 1sitıcı tablada 2 saat bekletilmiş, daha sonra ise saf su ile ICP-OES yöntemi kullanılarak sonuçlar ppm (parts per million) değeri cinsinden elde edilmiştir.

HC-01 (Artvin/Hopa) ve SC-01 (Trabzon/Sürmene) karotlardaki ağır metal konsantrasyonlarının startigrafik olarak derine doğru değişimlerinin gözlendiği seviyelerden elde edilen kavkı parçaları radyokarbon yaş tayini için ayırtlanmış ve örnekler analiz için Conventional Carbon Dating Laboratory (CCDL) Kiev/Ukrayna'ya gönderilmiştir. Analizler, Dr.
Mykhailo Buzynnyi tarafından Quantulus 1220TH kütle spektrometresi kullanılarak Skripkin ve Kovaliukh (1998)'in geliştirdiği Lithium carbite ve benzen solusyonu teknikleri yardımıyla, Ramsey ve Lee (2013)'ün OxCal v4.2.4 programı kullanılarak değerlendirilmiştir.

\section{Kirlilik Yük İndeksi (PLI; Pollution Load Index) Değerinin Saptanması}

PLI değeri, elementlerin dünya ölçeğinde antropojenik kirlenmenin seviyesini tespit emek için kullanılan bir katsayıdır (Tomlinson vd. 1980; Ray vd. 2006; Huerta-Diaz vd. 2008; Essien vd. 2009; Mohiuddin vd. 2010; Zhang vd. 2011; Galuszka vd. 2014). Bu değer ilk kez Tommilson vd. (1980) tarafından tanımlanmıştır. Bu değerin saptanması için ilk önce Kirlilik faktörünün (CF) bulunması gerekmektedir. CF değeri, çökellerin kalitesi ile ilgili olarak Hakanson (1980) tarafından ortaya atılmış olup, örneğin analizinden elde edilen sonucun $\left(\mathrm{C}_{\mathrm{i}}\right)$, dünya çapındaki genel oranları betimleyen Clarke veya ilgili ortalama kabuk değerlerine $\left(\mathrm{C}_{\mathrm{n}}\right)$ bölünmesi ile hesaplanır:

CF değerleri her element için bulunduktan sonra, PLI değeri analizi yapılmış her bir element için bulunan $\mathrm{CF}$ değerlerinin birbirleri ile çarpımının, element sayısına (n) bağlı kökünde değerlendirilir:

Bulunan sonucun $>1$ ( 1 'den büyük; kirlilik fazla) veya <1 (1'den küçük; kirlik az) olması durumuna göre yorum yapılmaktadır (Ray vd. 2006; Galuszka vd. 2014).

\section{Zenginleşme Faktörü (EF; Enrichment Factor) Değerinin Saptanması}

Zenginleşme faktörü zaman içinde değişik çevresel ortamların değerlendirilmesinde ve metal kirliliğinde antropojenik katkının hesaplanmasında da yoğun olarak kullanılan bir değerdir (Morillo vd., 2002; Adamo vd., 2005; Valdés vd., 2005). İlk 
kez Buat-Menard ve Chesselet (1979) tarafindan ortaya atılan bu faktörün hesaplanmasında ve değerlendirilmesinde, diğer kirlilik indekslerinden farklı olarak, bir referans element seçilerek normalleştirme yapılmaktadır. Normalleştirmede kullanılacak elementin seçimi konusunda kesin bir kabul olmamakla birlikte, genellikle alüminyum, demir, lityum, zirkon ve titanyum gibi jeokimyasal olarak aktif olmayan ve ince taneli materyallerde rahatlıkla rastlanabilen elementler kullanılır (Reinmann vd., 2000; Schiff ve Weisberg, 1999; Sutherland, 2000; Ray vd. 2006; Huerta-Diaz vd. 2008; Essien vd. 2009; Mohiuddin vd. 2010; Zhang vd. 2011; Galuszka vd. 2014). Bu çalışma kapsamında, Titanyum elementi karot içinde büyük varyasyonlar göstermemesi dolayısıyla referans element olarak değerlendirilmiştir. Zenginleşme faktörü, uluslararası yayınlarda Buat-Menard ve Chesselet (1979)'a sadık kalınarak aşağıdaki formül ile hesaplanır.

Formüldeki EF: Zenginleşme faktörü, $\mathrm{C}_{\text {Metal }}$ (Örnek): İlgili elementin konsantrasyonunu, $\mathrm{C}_{\mathrm{Ref}}$ (Örnek): referans olarak alınan elementin ölçülen konsantrasyonunu, $\mathrm{C}_{\text {Metal }}$ (Kabuk): İlgili elementin kabuktaki ardalan (background) değerini, $\mathrm{C}_{\text {Ref }}$ (Kabuk): referans olarak alınan elementin kabuktaki ardalan (background) değerini tanımlamaktadır. Genellikle hesaplanan EF değeri sonucunun 1'e yakın $(\mathrm{EF}<1)$ olması kabuk kökenine, 3-5 arasında olması tartışmalı olarak kabuk kökenine, $\mathrm{EF}<5$ 'ten büyük değerlerinde ise kabuk kökenli olmadığı yönünde bir kabul görmektedir (Galuszka vd. 2014; Halstead vd. 2000). EF için farklı standartlar ve referans aralıkları önerilsede, literatürde en yaygın şekilde Sutherland (2000)' in önerdiği aralıklar kullanılır. Söz konusu çalışmada EF değerleri zenginleşme ölçütüne göre 5 farklı kategoriye ayırılarak verilir; $\mathrm{EF}<2$, en az zenginleşme/kirlilik, $2 \leq \mathrm{EF} \leq 5$, orta zenginleşme/kirlilik; $5 \leq \mathrm{EF} \leq 20$, belirgin zenginleşme/kirlilik; $20 \leq \mathrm{EF} \leq 40$, çok yüksek zenginleşme/kirlilik; EF $>40$, son derece yüksek zenginleşme/kirlilik.
Ayrıca bu çalışma kapsamında hesaplanan PLI ve EF değerlerinin sonuçlarının elde edilmesinde, dünya standartlarında, benzer çalışmalarda en s1k kullanılan ve tane boyu, litoloji gibi faktörler gözetilerek ayrı ayrı hesaplanmış Turekian \& Wedepohl(1961)'in önerdiği ardalan (background) değerleri kullanılmıştır. Seçilen referans değerlerinin ilgili çalışmadan alınmasının bir diğer önemli sebebi, en sık kullanılmasının yanında, bu çalışmada sunulan sonuçların, Dünya'daki farklı alanlarda yapılan ve aynı değerler kullanılarak hesaplanmış benzer çalışmalarla kıyaslanmasının amaçlanmış olmasıdır.

\section{JEOKIMMYASAL ANALIZZ ÇALIŞMALARI}

Jeokimyasal analiz çalışmalarında, 3 farklı lokasyondaki karotlardan her birinde 15 numune olmak üzere toplamda 45 örneğin ağır metal (As, Ba, Sn, Pb, Cd, Cr, Ni, Sn, Ti ve $\mathrm{Zn}$ ) konsantrasyonlar1 ppm cinsinden elde edilmiştir. $\mathrm{Bu}$ elementlerden $\mathrm{As}, \mathrm{Ba}, \mathrm{Cr}, \mathrm{Ni}, \mathrm{Pb}$, Ti, Zn ve Cd oranları Çizelge 2'de verilmektedir. Özellikle Karadeniz'den alınan Sürmene ve Hopa karotlarındaki örneklerin 150-420 ppm arasında değişiklik gösteren yüksek Ti oranları dikkat çekicidir. Zn oranları ise Hopa karotunda 66-87 ppm, Sürmene'de ise $62-100$ ppm arasında değişiklik gösterir. Marmara karotunda (IZC-01) ise Ti değerleri, Karadeniz örneklerine oranla 10 ve 20 katına varan miktarlarda konsantrasyon düşüklüğü gösterir. Ni oranı Marmara karotunda, Karadeniz örneklerinden yaklaşık 3 kat fazla bir konsantrasyona sahip ve 27-44 ppm arasinda salınım sunar. Ba oranları ise en az Hopa, sonrasında Sürmene ve en yüksek değerlerde Marmara karotunda ölçülmüştür ve birbirlerine oranla yaklaşık 2 kat artış ile temsil edilirler (Çizelge 2). $\mathrm{Cd}$ değerleri ise, ölçüm sınırlarının yetersizliği dolayısıyla ayrımlaştırılamamış ve 0.3 ve $<0.1$ değerlerle temsil edildiği gözlenmiştir. Literatürde özellikle antropojenik kirliliğin ölçümünde en çok kullanılan $\mathrm{Pb}, \mathrm{Cr}, \mathrm{Zn}$ ve As gibi elementlerin 
değerleri dikkate alınmış ve bulunan değerlerin derine doğru değişimleri üzerinde durulmuştur. As değerleri 4-28 ppm gibi geniş bir aralıkta değişim sunmakta ise de, oransal olarak yine Marmara karotunun orta seviyelerinde en yüksek değerlerle ölçülmüştür. Cr oranları Karadeniz ait Sürmene ve Hopa karotlarında birbirlerine yakın değerlerle ve 8-19 ppm arasındaki konsantrasyonlarla karakteristiktir. Marmara'dan alınan İzmit karotunda ise, Karadeniz numunelerine oranla 3 kata varan bir $\mathrm{Cr}$ artışının bulunduğu gözlenmektedir. $\mathrm{Pb}$ oranlarının ortalamaları, lokasyon olarak Sürmene ve İzmit'te birbirlerine benzer, Hopa'da ise yarı yarrya az ve 6-14 ppm arasında değişen konsantrasyonlara sahiptir. Özellikle her 3 karottaki $\mathrm{Pb}$ ve $\mathrm{Zn}$ oranlarında, derine doğru bir azalmanın gözlenmesi dikkat çekicidir. Bu azalmanın hangi aralıklarda olduğu ve nasıl salınım gösterdiği, değişimlerin elde edilen radyometrik yaşlar ile hesaplanan olası sedimantasyon hızlarına bağlı olarak, hangi zaman aralıklarında gerçekleştiği, tartışma ve sonuç bölümünde irdelenmiştir.

Çizelge 2. Karotlardan alınan örneklerde yapılan jeokimyasal analiz sonuçları.

Table 2. Geochemical analysis results of the samples taken from the cores.

\begin{tabular}{|c|c|c|c|c|c|c|c|c|c|c|}
\hline \multirow{2}{*}{ Karot } & \multirow{2}{*}{ Örnek } & \multirow{2}{*}{$\begin{array}{c}\text { Derinlik } \\
(\mathrm{cm})\end{array}$} & \multicolumn{8}{|c|}{ Ağır metallerin konsantrasyonu (ppm) } \\
\hline & & & As & $\mathrm{Ba}$ & $\mathrm{Cr}$ & $\mathrm{Ni}$ & $\mathrm{Pb}$ & $\mathrm{Ti}$ & $\mathrm{Zn}$ & $\mathrm{Cd}$ \\
\hline \multirow{15}{*}{$\begin{array}{c}\text { Artvin/ Hopa } \\
\text { Karadeniz } \\
\text { HC-01 }\end{array}$} & H1 & 1.5 & 13 & 16 & 14 & 15 & 11 & 330 & 75 & 0.2 \\
\hline & $\mathrm{H} 2$ & 4.5 & 10 & 19 & 16 & 18 & 14 & 380 & 87 & 0.1 \\
\hline & H3 & 7.5 & 11 & 16 & 16 & 18 & 12 & 420 & 73 & 0.1 \\
\hline & $\mathrm{H} 4$ & 10.5 & 4 & 17 & 15 & 17 & 9 & 400 & 76 & $<0.1$ \\
\hline & H5 & 13.5 & 5 & 17 & 14 & 17 & 8 & 310 & 68 & $<0.1$ \\
\hline & H6 & 17.5 & 6 & 17 & 13 & 15 & 7 & 370 & 67 & $<0.1$ \\
\hline & H7 & 20.5 & 5 & 16 & 14 & 22 & 6 & 370 & 67 & $<0.1$ \\
\hline & H8 & 23.5 & 6 & 17 & 14 & 17 & 8 & 340 & 69 & $<0.1$ \\
\hline & H9 & 28.5 & 6 & 21 & 16 & 22 & 9 & 280 & 70 & $<0.1$ \\
\hline & H10 & 31.5 & 6 & 19 & 16 & 19 & 8 & 300 & 71 & $<0.1$ \\
\hline & H11 & 34.5 & 5 & 18 & 14 & 17 & 7 & 350 & 66 & $<0.1$ \\
\hline & H12 & 37.5 & 5 & 17 & 15 & 18 & 7 & 330 & 70 & $<0.1$ \\
\hline & H13 & 47.5 & 6 & 16 & 14 & 17 & 7 & 360 & 67 & $<0.1$ \\
\hline & H14 & 67.5 & 5 & 14 & 13 & 14 & 6 & 350 & 67 & $<0.1$ \\
\hline & H15 & 87.5 & 5 & 16 & 12 & 14 & 7 & 400 & 66 & $<0.1$ \\
\hline
\end{tabular}


Çizelge 2 devam ediyor/continued

\begin{tabular}{|c|c|c|c|c|c|c|c|c|c|c|}
\hline \multirow{15}{*}{$\begin{array}{l}\text { Trabzon/Sürmene } \\
\text { Karadeniz } \\
\text { SC-01 }\end{array}$} & S1 & 1.5 & 7 & 27 & 11 & 11 & 18 & 160 & 74 & 0.2 \\
\hline & S2 & 4.5 & 7 & 26 & 12 & 11 & 17 & 170 & 71 & 0.2 \\
\hline & S3 & 7.5 & 8 & 30 & 16 & 12 & 21 & 140 & 84 & 0.2 \\
\hline & S4 & 10.5 & 13 & 33 & 15 & 14 & 24 & 150 & 100 & 0.3 \\
\hline & S5 & 13.5 & 14 & 32 & 19 & 13 & 23 & 140 & 88 & 0.2 \\
\hline & S6 & 17.5 & 11 & 33 & 15 & 15 & 22 & 160 & 86 & 0.2 \\
\hline & S7 & 20.5 & 11 & 33 & 13 & 14 & 23 & 160 & 81 & 0.2 \\
\hline & S8 & 23.5 & 9 & 30 & 13 & 14 & 22 & 160 & 77 & 0.2 \\
\hline & S9 & 28.5 & 10 & 34 & 13 & 15 & 23 & 170 & 77 & 0.2 \\
\hline & $\mathrm{S} 10$ & 31.5 & 9 & 31 & 13 & 14 & 23 & 150 & 73 & 0.1 \\
\hline & S11 & 41.5 & 7 & 26 & 11 & 12 & 17 & 160 & 66 & 0.1 \\
\hline & $\mathrm{S} 12$ & 61.5 & 14 & 30 & 14 & 15 & 19 & 160 & 70 & 0.1 \\
\hline & $\mathrm{S} 13$ & 81.5 & 8 & 30 & 13 & 14 & 20 & 160 & 74 & 0.2 \\
\hline & S14 & 101.5 & 8 & 27 & 10 & 11 & 16 & 150 & 79 & 0.1 \\
\hline & S15 & 121.5 & 6 & 24 & 8 & 9 & 13 & 180 & 62 & 0.1 \\
\hline \multirow{15}{*}{$\begin{array}{c}\text { İzmit/Başiskele } \\
\text { Marmara } \\
\text { IZC-01 }\end{array}$} & M1 & 1 & 7 & 35 & 32 & 56 & 21 & 19 & 60 & $<0.1$ \\
\hline & M2 & 3 & 6 & 43 & 33 & 58 & 20 & 19 & 61 & $<0.1$ \\
\hline & M3 & 6 & 4 & 55 & 39 & 66 & 20 & 23 & 67 & $<0.1$ \\
\hline & M4 & 10 & 4 & 50 & 40 & 68 & 20 & 19 & 67 & $<0.1$ \\
\hline & M5 & 14 & 5 & 62 & 41 & 72 & 21 & 21 & 67 & $<0.1$ \\
\hline & M6 & 18 & 6 & 48 & 44 & 77 & 22 & 23 & 71 & 0.1 \\
\hline & M7 & 22 & 5 & 38 & 41 & 68 & 22 & 24 & 69 & $<0.1$ \\
\hline & M8 & 26 & 7 & 54 & 42 & 68 & 18 & 22 & 67 & 0.1 \\
\hline & M9 & 30 & 28 & 32 & 42 & 77 & 15 & 19 & 66 & 0.2 \\
\hline & M10 & 34 & 19 & 37 & 42 & 79 & 15 & 20 & 65 & 0.2 \\
\hline & M11 & 38 & 7 & 56 & 37 & 82 & 13 & 20 & 57 & 0.2 \\
\hline & M12 & 50 & 8 & 74 & 31 & 69 & 11 & 21 & 51 & 0.2 \\
\hline & M13 & 80 & 5 & 74 & 29 & 64 & 10 & 22 & 47 & 0.1 \\
\hline & M14 & 120 & 7 & 75 & 27 & 61 & 10 & 22 & 46 & 0.2 \\
\hline & M15 & 170 & 18 & 55 & 30 & 69 & 11 & 25 & 48 & 0.2 \\
\hline
\end{tabular}

\section{JEOLOJİK BULGULAR}

Karot örnekleri üzerinde yapılan jeolojik incelemeler, genelde litolojik, sedimantolojik ve paleontolojik veriler 1şı̆̆ında değerlendirilmiştir. $\mathrm{Bu}$ bağlamda, İzmit Körfezine ait olan karot örneğinin (IZC-01), Karadeniz'e ait karotlardan daha ince taneli sedimanlardan oluştuğu görülür. Litolojik olarak ince kum, kil ve çamurdan yapılı olan karotta genel bir düzen içinde ardalanma mevcuttur (Şekil 3). Karotta farklı litolojilerde de olsa baskın renk siyahımsı gridir. Karotun yüzeyden 135-150 cm arasındaki tortullarda net bir şekilde ters derecelenme olduğu gözlenmektedir. Organik madde bakımından, karotun genelinde eş oranda kavkılı canlı kalıntılarına rastlanmıştır. Sadece Marmara karotu özelinde, boyutları 0.5-1.5 cm arasında değişen jips kristallerinin varlığı dikkat 
çekicidir. Hatta bu jips kristallerinin boyları, karotun stratigrafik olarak üst seviyelerinde, alt bölümlerine oranla daha iri kristallere sahiptir. Sürmene karotunda (SC-01) ise kaba kumdan çok ince kuma değişen ve genelde baskın olarak kum boyu tortullardan yapılı bir litoloji hâkimdir. Karotun ilk 15 cm'lik bölümü ise yeşilimsi gri renkli çamurdan yapılıdır. Karotta, birimlerin tane bileşenleri genelde mika grubu litik kaya kırıntılarınca zengindir. İzmit karotuna benzer şekilde, Sürmene karotunun 60-70 cm'leri arasında orta kumdan kaba kuma bir ters derecelenme söz konusudur. Karotun orta üst seviyesindeki bazı orta kumlarda dalgalı laminasyon olağandır. Sürmene karotu, İzmit karotundan çeşitlilik ve bolluk açısından, paleontolojik olarak daha zengindir. Kavk1 bolluğu, istifte alttan üste belirgin bir farklılaşma göstermese de tür ve cins bakımından bir azalma olduğu açıkça görülmektedir. Hopa karotu ise, litolojik olarak çok kaba kumdan çamura değişen bir tane boyu dağılımı göstermektedir. Karot stratigrafisinde, istifin nispeten üst bölümü alt bölümlerine oranla daha kaba kırıntılıdır. Bu karotta, diğer iki karotun aksine 70- $60 \mathrm{~cm}$ aralığında yukarıya doğru ince kumdan çok ince kuma doğru normal bir derecelenme gözlenir. Karotun üst seviyelerinde aynı Sürmene karotunda olduğu gibi dalgalı laminasyon gösteren $10 \mathrm{~cm}$ kalınlığında ince kumdan yapılı bir seviye de bulunmaktadır. Hopa karotu paleontolojik olarak, gerek kavkı bolluğu gerekse tür ve cins çeşitliliği bakımından en zengin karot olmakla beraber, diğer iki karottan farkl1l1k göstermektedir. Bu farklılaşma kendi içinde Sürmene'den az, İzmit karotundan ise fazladır. Karotun üst seviyelerindeki paleontolojik bolluk ve çeşitlilik, alt bölümüne göre oldukça fazladır. Bunun yanında, sadece Hopa karotunun yüzeye yakın ilk $10 \mathrm{~cm}$ 'lik bölümünde bitkisel kalıntı ürünlerine rastlanmıştır (Şekil 3).

\section{TARTIŞMA VE SONUÇLAR}

Karadeniz ve Marmara'daki 3 farklı lokasyondan alınan karot örneklerinin jeokimyasal analiz sonuçlarına göre, İzmit Körfezi'ndeki sediman örneklerinin Sürmene ve Hopa örneklerine oranla daha fazla As, $\mathrm{Ba}, \mathrm{Cr}$, Ni gibi ağır metal kirlenmesine maruz kaldığ 1 gözlenmektedir. Sürmene ve Hopa karotlarından alınan örneklerin Titanyum konsantrasyonları, İzmit Körfezi örneklerinin sonuçlarına oranla oldukça fazladır. Karedeniz özelinde titanyum elementinin bu yüksek konsantrasyonu, Çağatay vd. (1987) tarafindan da açıkça vurgulanmaktadır. Çalışmacılar, güncel sedimanlar üzerinde yaptıkları jeokimyasal analizlerde en düşük Ti değerinin 300 ppm, en yüksek değerinin ise 4000 ppm olduğunu belirterek, bu yüksek Ti anomalisini, bazik volkanik kökenli kırıntı malzeme ile ilişkili olduğunu savunurlar. Benzer şekilde bu çalışma kapsamında da Karedeniz örneklerinden elde edilen yüksek Ti konsantrasyonunun antropojenik bir kirlenme ile ilişkili olmadığı, beslenme alanı kaya litolojisine ait bileşimsel bir katkıdan kaynaklandığ1 düşünülmüş ve bu nedenle kirlilik hesaplarında $\mathrm{Ti}$ elementinin konteminasyonu göz ardı edilmiştir. Hatta Ti elementinin karotlar içersindeki varyasyonlarının değişmemesi, bu elementin Zenginleşme Faktörü hesaplamalarında referans element olarak kullanılmasına uygunluk sağlamıştır. 

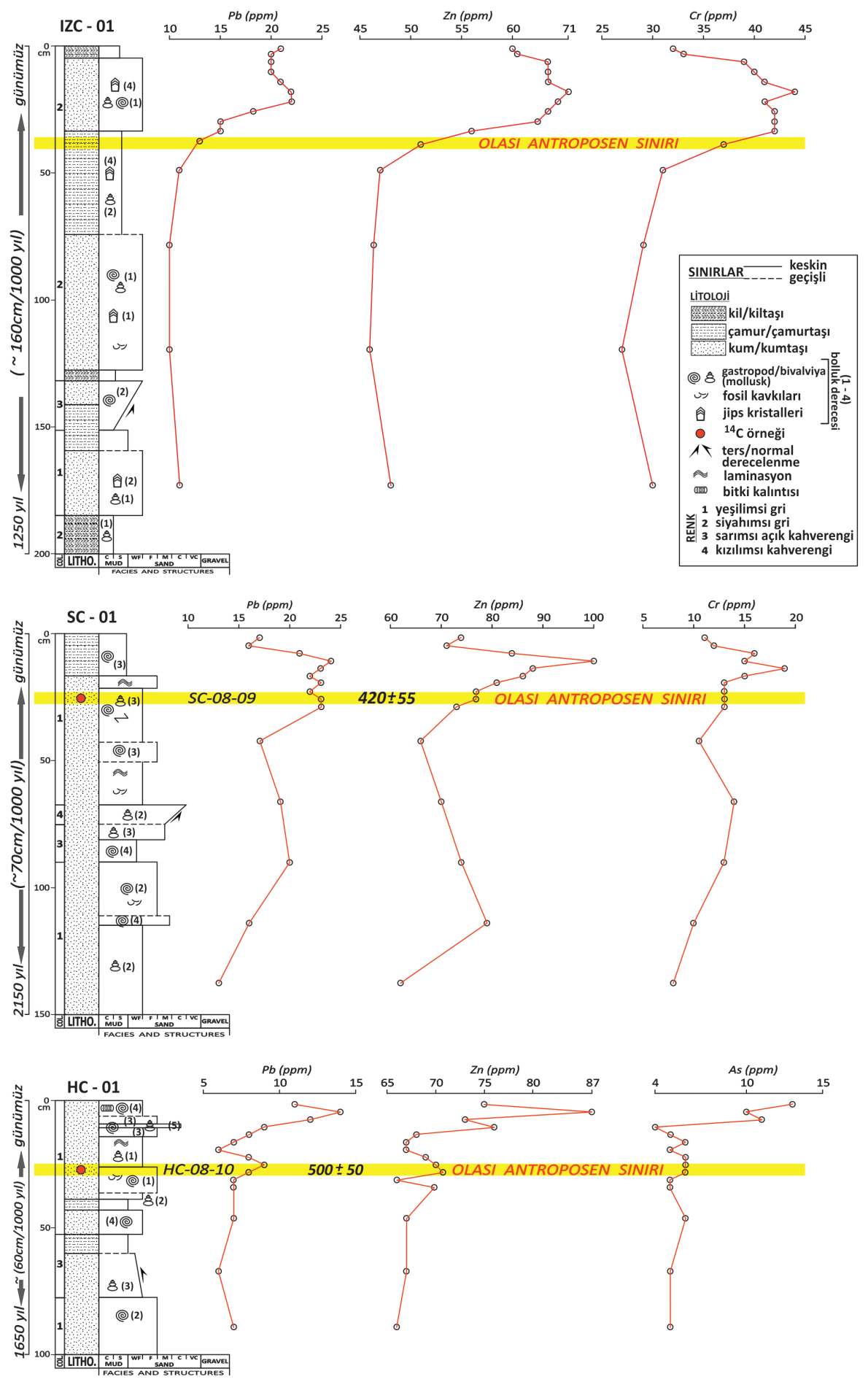

Şekil 3. İzmit (IZC-01), Sürmene (SC-01) ve Hopa (HC-01) karotlarının logları ve karotlardan alınan örneklerin, ağır metal konsantrasyonlarındaki derinliğe bağlı dağılımları.

Figure 3. Logs of the cores and vertical distribution of the heavy metal concentration of samples taken from Izmit (IZC-01), Sürmene (SC-01) ve Hopa (HC-01) cores. 
Karot örneklerinde $\mathrm{As}, \mathrm{Ba}, \mathrm{Pb}, \mathrm{Cr}$, Ni ve $\mathrm{Zn}$ elementlerinin analiz sonuçlarından elde edilen değerler kullanılarak 3 farklı lokasyon için PLI değerleri hesaplanmış ve elde edilen değerler Çizelge 3'de gösterilmiştir. Bu sonuçlara göre; İzmit Körfezi, Sürmene ve Hopa'ya ait örneklerden elde edilen PLI değeri 1< PLI (1'den büyük ve sırasıyla; 3.255, 2.195 ve 1.706 olarak hesaplanmıştır. Sonuçlar alanların kirli bölge grubuna dahil edilmesi gerektiği yönündedir. Bunun yanında, orantısal olarak İzmir Körfezi'ne ait karotun, kirlilik yönünden en yüksek değere sahip olduğu gözlenirken, Hopa karotu örneklerinin de PLI değerinin Sürmene karotuna göre düşük olduğu görülmektedir. Dolayısıyla, kirlilik bazında İzmit Körfezi kirli, Sürmene daha az kirli ve Hopa ise en az kirli lokasyon olarak değerlendirilmektedir.

Özellikle üç farklı lokasyon için elde edilen PLI değerinin kirlilik sınırının üzerinde olması ve kirlilik seviyesinin anlaşılması açısından, Dünya'nın farklı bölgelerinde benzer yöntemlerle yapılan çalışmalardan elde edilen sonuçlarla karşılaştırılması gereğini doğurmaktadır. Ray vd. (2006) tarafından Hindistan'da yapılan çalışmada PLI değerinin 0.34 ile 1.03 arasında değiştiği görülmektedir. $\mathrm{Bu}$ durumda İzmit Körfezin'in, Hindistan'ın Kakinada, Godavari, Coringa ve Gaderu kıyılarından daha fazla kirlenmiş olduğu yorumu yapılabilir. Aynı şekilde, Essien vd. (2009) Nijerya'nın güneyindeki Cross Nehri ve Mangrove Bataklığı çevresindeki PLI değerlerinin 1.26 ile 1.76 arasında değiştiğini vurgulamaktadır. Mohiuddin vd. (2010) Japonya, Yokohoma'da yaptıkları çalışmalarda 1.24-7.65 arasında, Huerta-Diaz vd. (2008) Baja California'da yaptıkları çalışmalarda 1.01-4.29 arasında, Bhuiyan vd. (2010) Bangladeş'te yaptıkları çalışmalarda 1.67-4.02, Rashed (2010) Mısır'ın güneydoğusunda yaptıkları çalışmalarda ise 0.642.92 arasında değişen değerler rapor etmektedir. İzmit Körfezi'ne ait PLI değerinin, Dünya'da kirliliği bildirilen alanlardaki değerler ile benzer olduğu görülmektedir. Fakat kirliliği aşır1 derecede ön plana çıkmış Yokohama (Japonya) ve Baja (Meksika) gibi alanlardaki oranlara kıyasla, İzmit Körfezi'nin ağır metal konsantrasyonuna bağlı kirlilik seviyesinin ortalama değerlerin altında kaldığı tespit edilmiştir. $\mathrm{Bu}$ sonuçlar doğrultusunda, İzmit Körfezi'nin Dünya'nın birçok farklı bölgesine kıyasla kirlilik seviyesinin üstünde ya da ortalamasında yer aldığı, fakat çok kirli alanlardan daha az bir kirliliğe sahip olduğu gözlenmiştir.

Yine karot örneklerinden elde edilen As, $\mathrm{Ba}, \mathrm{Cr}, \mathrm{Ni}, \mathrm{Pb}$ ve $\mathrm{Zn}$ elementlerinin ağır metal konsantrasyonlarından yola çıkarak 3 farklı lokasyon için Zenginleşme Faktörü (EF) değerleri hesaplanmış ve sonuçlar Çizelge 4'de verilmiştir. Elde edilen sonuçlar doğrultusunda Sutherland (2000)'e göre İzmit Körfezinde As, Ni ve Cr elementlerinin belirgin bir zenginleşme, $\mathrm{Pb}$ ve $\mathrm{Zn}$ elementlerinin orta derecede zenginleşme, $\mathrm{Ba}$ elementinin ise yetersiz zenginleşme gösterdiği saptanmıştır. Sürmene lokasyonunda ise As, $\mathrm{Ba}$ ve $\mathrm{Cr}$ elementinin yetersiz zenginleşme gösterdiği, fakat $\mathrm{Ni}, \mathrm{Pb}$ ve $\mathrm{Zn}$ elementlerinde belirgin bir zenginleşmenin olduğu gözlenmiştir. Sürmene lokasyonuna benzer şekilde Hopa lokasyonunda $\mathrm{As}, \mathrm{Ba}, \mathrm{Cr}$ ve $\mathrm{Pb}$ elementlerinde yetersiz zenginleşme olduğu gözlenirken, $\mathrm{Ni}$ ve $\mathrm{Zn}$ elementleri bakımından belirgin bir zenginleşmenin olduğu saptanmıştır. Diğer yandan, İzmir Körfezi, Sürmene ve Hopa'dan alınan karot örneklerinden elde edilen EF değerleri, kirlilik seviyesinin anlaşılabilmesi açısından Dünya'nın farklı bölgelerinde benzer yöntemlerle yapılan çalışmalardan elde edilen sonuçlarla karşılaştırılmıştır. Szefer vd. (1998) tarafından Polonya'nın Puck Körfezi'nde yapılan çalışmada $\mathrm{Zn}$ elementi için hesaplanan EF değerinin 1.7-14.6 arasında değiştiği belirtilmektedir. $\mathrm{Bu}$ duruma İzmir Körfezi, Sürmene ve Hopa lokasyonlarında Zn elementi için hesaplanan EF değerinin Puck Körfezi'nden elde edilen değerlere benzer sonuçlar gösterdiği anlaşılmaktadır. Aynı 
şekilde Szefer vd. (1998) Puck Körfezi için Pb elementi için hesaplanan EF değerinin 2.4-24 arasında değişiklik gösterdiğini belirtmektedir. $\mathrm{Bu}$ bağlamda Pb elementinin Hopa lokasyonunda Puck Körfezi'ne oranla daha az miktarda zenginleştiği, İzmit Körfezi ve Sürmene lokasyonlarının ise benzer aralıklarda salındığı görülmektedir. Aynı şekilde Abrahim ve Parker (2008) Yeni Zelanda, Auckland (Tamaki)'de yapıtıkları çalışmada $\mathrm{Pb}$ ve $\mathrm{Zn}$ elementleri için EF değerinin sırasıyla 0.76.8 ve $2.2-4.0$ aralığında olduğunu, Spencer vd. (2003) ise Büyük Britanya'nın Kent bölgesinde yapıtıkları çalışmada $\mathrm{Pb}$ ve $\mathrm{Zn}$ elementleri için elde edilen EF değerinin sirasıyla $0.9-10$ ve 0.8-2.6 olduğu bilinmektedir. Bu durumda her üç lokasyon için de $\mathrm{Pb}$ elementindeki zenginleşmenin, Yeni Zelanda'dan ve Büyük Birtanya'nın Kent bölgesinden elde edilen değerlerler ile benzer olduğu, ancak Zn elementindeki zenginleşmenin Yeni Zelanda ve Büyük Birtanya'nın Kent bölgesine kıyasla daha fazla olduğu saptanmıştır. Sonuç olarak gerek Karadeniz gerekse Marmara örneklerindeki $\mathrm{Zn}$ ve $\mathrm{Pb}$ elementleri zenginleşme faktörlerinin dünyadaki kirliliği $\mathrm{EF}$ cinsinden ortaya konulan alanlarla, çoğunlukla benzer özellikler taşıdığı saptanmıştır.

Çizelge 3. Hopa, Sürmene ve İzmit karotlarından ölçülen PLI değerleri (CF, kontaminasyon faktörü, $\mathrm{C}_{\mathrm{i} / \mathrm{o}}(\mathrm{ppm})$ değerleri ilgili element için karot içindeki ortalama konsantrasyon hesaplanarak kullanılmıştır).

Table 3. PLI values measured on the Hopa, Sürmene and Izmit cores sites $\left(C_{i / o}\right.$ values (ppm) were calculated mean concentration values for the corresponding elements in the core).

\begin{tabular}{|c|c|c|c|c|c|c|c|c|}
\hline \multirow{2}{*}{\multicolumn{2}{|c|}{$\begin{array}{c}\text { Karot (Bölge) } \\
\text { Ba }\end{array}$}} & \multicolumn{6}{|c|}{ Konsantrasyon (ppm) } & \multirow{2}{*}{ PLI } \\
\hline & & \multirow{2}{*}{$\begin{array}{c}\mathbf{C r} \\
17.06 \\
\end{array}$} & \multirow{2}{*}{\begin{tabular}{c|}
$\mathbf{C d}$ \\
14.40 \\
\end{tabular}} & \multirow{2}{*}{$\begin{array}{c}\mathbf{N i} \\
0.133 \\
\end{array}$} & \multirow{2}{*}{$\begin{array}{c}\mathbf{P b} \\
17.33 \\
\end{array}$} & \multirow{2}{*}{$\begin{array}{c}\mathbf{Z n} \\
8.06 \\
\end{array}$} & \multirow[b]{2}{*}{70.60} & \\
\hline Artvin/Hopa & $\mathrm{C}_{\mathrm{i} / \mathrm{o}}$ & & & & & & & \multirow{2}{*}{0.592} \\
\hline$(\mathrm{HC}-01)$ & $\mathrm{CF}$ & 0.026 & 0.115 & 4.444 & 0.298 & 0.403 & 26.148 & \\
\hline \multirow{2}{*}{$\begin{array}{c}\text { Trabzon/Sürmene } \\
\text { (SC-01) }\end{array}$} & $\mathrm{C}_{\mathrm{i} / \mathrm{o}}$ & 29.73 & 12.46 & 0.1733 & 12.93 & 20.06 & 77.46 & \multirow{2}{*}{0.715} \\
\hline & $\mathrm{CF}$ & 0.0467 & 0.0997 & 5.666 & 0.2229 & 1.0033 & 28.691 & \\
\hline \multirow{2}{*}{$\begin{array}{c}\text { İzmit/Başiskele } \\
\text { (IZC-01) }\end{array}$} & $\mathrm{C}_{\mathrm{i} / \mathrm{o}}$ & 52.53 & 36.66 & 0.1333 & 68.93 & 16.60 & 60.60 & \multirow{2}{*}{1.417} \\
\hline & $\mathrm{CF}$ & 0.0825 & 0.310 & 14.03 & 1.118 & 0.9 & 22.44 & \\
\hline
\end{tabular}

Çizelge 4. Hopa, Sürmene ve İzmit karotlarından ölçülen elementlere ait EF değerleri.

Table 4. EF values of measured elements on the Hopa, Sürmene and İzmit cores.

\begin{tabular}{ccccccc}
\hline \multirow{2}{*}{ Karot (Bölge) } & \multicolumn{7}{c}{ EF (Zenginleșme Faktötü) } \\
\cline { 2 - 7 } & $\mathbf{A s}$ & $\mathbf{C r}$ & $\mathbf{B a}$ & $\mathbf{N i}$ & $\mathbf{P b}$ & $\mathbf{Z n}$ \\
\hline Artvin/Hopa (HC-01) & 0.67 & 7.66 & 0.1 & 19.06 & 3.9 & 4.44 \\
\hline Trabzon/Sürmene (SC-01) & 1.84 & 0.94 & 0.39 & 16.37 & 5.08 & 5.6 \\
\hline İzmit/Başiskele (IZC-01) & 13.11 & 0.46 & 1.7 & 9.82 & 1.36 & 5.0 \\
\hline
\end{tabular}


Ayrıca, İzmit Körfezine ait karot örneğinin içerisinde daha önce de belirtildiği gibi boyutları $0.5-1.5 \mathrm{~cm}$ arasında değişen jips kristallerinin varlığ içinde yapılan önceki çalışmalarda da jips kristalinin varlığı rapor edilmektedir (Stanley ve Blainpied, 1980; McHugh vd. 2008). Özellikle Stanley ve Blainpied (1980)'in vurguladiğ 1 ve çalışmasında G6 nolu karotta gözlediğini belirttiği jips kristalleri, karotun üst seviyelerinde gözlenememektedir. Fakat bu çalışma kapsamında değerlendirilen IZC-01 karotunda hemen hemen her seviyede jips kritalizasyonuna rastlanmış, hatta bu jips kristallerinin bolluğunda ve iriliğinde karot stratigrafisinde daha genç katmanlara gidildikçe bir artış olduğu görülmüştür. Van Driessche vd. (2011) jips kristalinin, düşük sıcaklıkta $\left(<55^{\circ} \mathrm{C}\right.$ 'de) ölçülebilir büyüme oranının $1.4 \pm 0.2 \times 10^{-5} \mathrm{~nm} / \mathrm{s}$ olduğunu belirtir. Bu orandan yola çıkarak, $1.5 \mathrm{~cm}$ 'lik bir kristalin oluşabilmesi için yeterli süre yaklaşık 2800-3000 y1l olarak hesaplanmaktadır. Bu doğrultuda, karot içindeki jips kristallerinin bulundukları stratigrafik pozisyonların, olası sedimantasyon hızı ile ilişkisi de orantılı gözükmemektedir. Literatürde, jips kristallerinin oluşumunun ve büyüme hızının artmasının gerek hava gerekse su kirliliği ile tetiklendiği ve ilişkilendirildiği bilinmektedir (Charola vd. 2007; Török vd. 2007; Gomez-Heras vd. 2008; Marszałek vd. 2014). Bu veriler ışı̆̆ında, İzmit Körfezi karotundaki jips kristallerinin antropojenik kökenli bir etken sonucu gelişmiş olabileceği sonucuna varılması gerekliliği doğmaktadır. Buna ilaven, karotlar içerisindeki kavkılı canlı kalıntılarının bolluk ve çeşitliliği de bunu destekleyen özellikler göstermektedir. İzmit Körfezi karotunda paleontolojik örneklere ender miktarda rastlanırken, Hopa ve Sürmene karotlarında ise İzmit Körfezi'ne kıyasla bu kalıntılarla daha sık karşılaşılmaktadır. Bu jeolojik gözlemler ile kirlilik bazında hesaplanan PLI değerleri de oldukça uyumludur.

Her karot kendi içinde değerlendirildiğinde, özellikle $\mathrm{Pb}, \mathrm{Cr}, \mathrm{Zn}$ ve As gibi ağır minerallerin sonuçlarının, karotlardaki derinliğe bağlı değişiminde bariz bir farkl1lık olduğu ve bu farklılığın derine doğru konsantrasyonlarda azalma şeklinde gerçekleştiği görülür (Şekil 3). $\mathrm{Bu}$ değişimler, Hopa karotunda (HC-01), Pb için 14-6 ppm, Zn için 87-66 ppm ve As için 13-5 ppm arasında salınır. Sürmene karotunda (SC01) ise, konsantrasyonların $\mathrm{Pb}$ için 24-13 ppm, Zn için 100-62 ppm, Cr için 16-8 ppm arasında değiştiği gözlenmektedir. İzmit karotunda (IZC01) $\mathrm{Pb}$ için 23-10 ppm arasında gerçekleşirken, Zn için 71-46 ppm ve Cr için 44-27 ppm bandında gerçekleşmektedir. Evans vd. (1989)'un Marmara karotlarında da, $\mathrm{Pb}, \mathrm{Cu}, \mathrm{Cr}$ ve $\mathrm{Zn}$ için derine doğru bir konsantrasyon azalması olduğu görülür. Fakat Karadeniz özelinde, yöntemsel olarak benzer bir bilimsel çalışma bulunmadığından, karşılaştırma yapılamamıştır. Bunun dışında, her 3 karotta da ilgili elementler için bu azalmaların bariz bir şekilde anomali gösterdiği bir hat ortaya çıkmaktadır (Şekil 3). Sürmene ve Hopa karotlarinda bu seviye hemen hemen birbirlerine yakın ve 20-25 cm arasındaki bir hatta gerçekleşirken, İzmit karotunda ise orantısal olarak daha derinde ve 40-45 cm arasında kaldığ 1 görülmektedir. Sürmene ve Hopa karotlarında, anomalilerin gözlendiği derinliklerden elde edilen kavkı parçalarının radyokarbon yaşları sırasıyla $420 \pm 55$ (GÖ) ve 500 \pm 50 (GÖ), bu verilerden elde edilen kalibre yaşlar ise Sürmene karotu için MS 1412 (\% 66.9) - MS1542 (\% 28.5) ve Hopa karotu için MS 1385 (\% 77.4) - MS 1307 (\% 18.0) olarak hesaplanmıştır (Şekil 4). 


\begin{tabular}{cccccccc}
\hline Karot & Örnek No & Lab. No & Benzen miktarı (gr) & Süre (dakika) & $\begin{array}{c}\text { Örnek sayım } \\
\text { mikatarı (CPM) }\end{array}$ & $\begin{array}{c}\text { Radyokarbon yaşı } \\
\text { (GÖ) }\end{array}$ & $\begin{array}{c}\text { Kalibre yaşı } \\
\text { (MS) }\end{array}$ \\
\hline $\begin{array}{c}\text { Sürmene } \\
\text { SC -01 }\end{array}$ & SC-08-09 & $\begin{array}{c}\text { IHME- } \\
3181\end{array}$ & 0.1314 & 2500 & 0.866 & $420 \pm 55$ & $1412(\% 66.9)$ \\
\hline $\begin{array}{c}\text { Hopa } \\
\text { HC -01 }\end{array}$ & HC-08-10 & $\begin{array}{c}\text { IHME- } \\
3182\end{array}$ & 0.2945 & 2500 & 1.673 & $500 \pm 50$ & $\begin{array}{c}1385(\% 77.4) \\
(\% 28.5)\end{array}$ \\
\hline
\end{tabular}
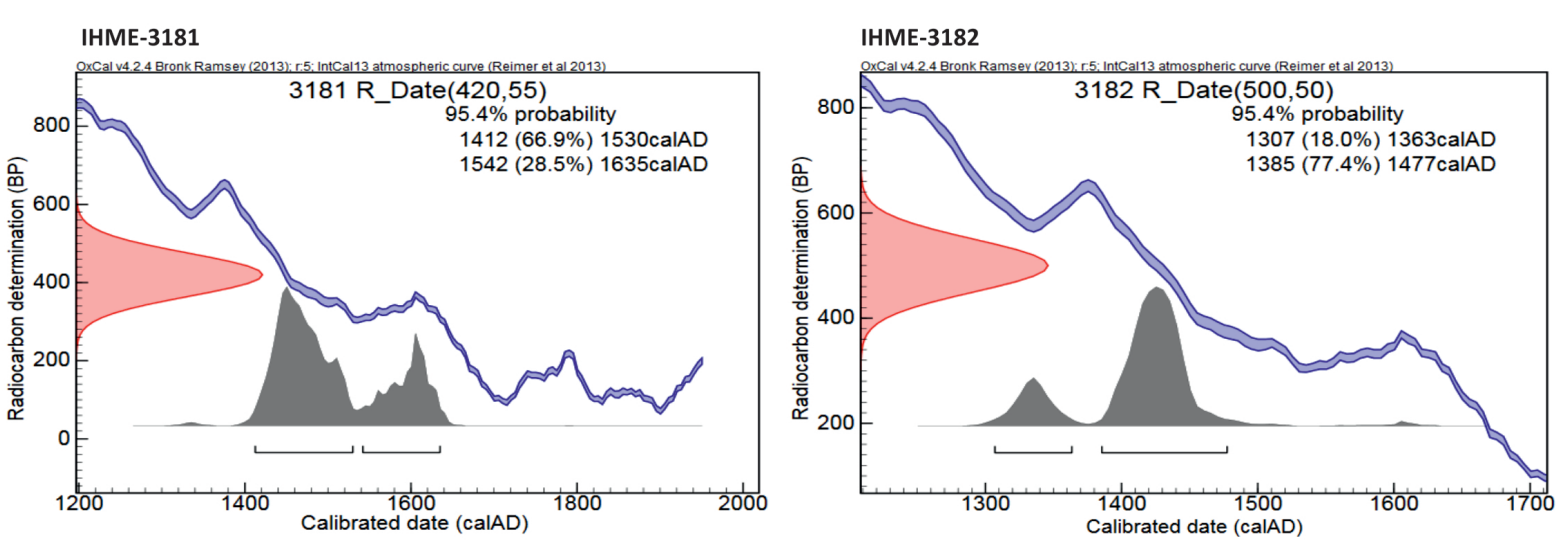

Şekil 4. Sürmene ve Hopa karotlarından alınan kavkı örneklerinin radyokarbon yaşlarına ait veriler ve yaşların olasılık grafikleri. Analiz ölçümlemeleri için OxCal v4.2.4 programı Ramsey ve Lee (2013)'den, atmosferik eğri ise Reimer vd. (2013)'den alınmıştır.

Figure 4. Sequential radiocarbon age data on shell samples collected from the Sürmene and Hopa cores and probability distribution of calibrated age diagramme. OxCal v4.2.4 programme taken from Ramsey \& Lee (2013) and atmospheric curve from Reimer et al. (2013).

Ayrıca bu sınırların jeolojik yaş ilişkilerinin denetlenebilmesi için, değerlendirilen karotların yakın çevresinde yapılan ve literatürde doğrudan ya da dolaylı bir şekilde sedimantasyon hızlarına değinilen çalışmalar irdelenmiş ve bu hızlar karotların boylarına göre oranlanarak, stratigrafik olarak olası bir jeolojik yaş ilişkisi kurulmaya çalışılmıştır. Marmara Denizi içindeki çökelimin hızını çeşitli yöntemler kullanarak belirleyen çalışmalar oldukça yaygındır. Marmara için sedimantasyon hızına yönelik ilk açılama Koreneva (1971)'in spor ve polenleri kullandığ1 çalışmasında verilir. Çalışmacı, 2 metreyi aşan karotların tabanında bile, Holosen sınırına inilmediğini dolayısı ile yüksek bir sediment akümülasyonunun olması gerektiğini savunur. Stanley ve Blanpied (1980), radyokarbon verilerine dayanarak kuzeydoğu Marmara şelfinde 4500 - 5000 y1l arasinda en az $70 \mathrm{~cm} / 1000$ yıllık bir hız önerir. Aynı çalışmada, 4 karotun da, farklı derinliklerden elde edilen radyometrik yaş verileri gözetilerek, hızların 2.5-23 cm/1000 yıl aralığında değiştiği hesaplanabilmektedir. Evans vd. (1989)'ın aynı kuzeydoğu Marmara şelfinde yaptı̆̆ çalışmasında verilen sediment ağırlıklarından yola çıkarak 100-140 cm/1000 y1l gibi değerler hesaplanabilir. Marmara Denizi özelinde ve doğrudan sedimantasyon hızını belirlemeye yönelik en kapsamlı çalışmalardan biri Ergin vd. (1994)'tür. Çalışmacılar, Marmara'nın güneyinde, kuzeyinde ve merkezinde aldıkları karotlarda, ${ }^{210} \mathrm{~Pb}$ yöntemiyle yaşlar elde etmişler ve bunları sedimantasyon hızlarını bulmak için yorumlamışlardır. Çalışmanın sonucunda farklı alanlarda, ortalama $8-104 \quad \mathrm{~cm} / 1000$ y1l gibi hızlar elde etmişlerdir. Gökmen vd. (1996) ise benzer alanlarda ve aynı yöntemle, sediment ağırlıklarından yola çıkarak, 60-260 cm/1000 
y1l gibi hızlar rapor etmektedir. Aksu vd. (2002) verilerinden kuzey Marmara için 2-60 cm/1000 y1l gibi hizlar hesaplanabilmektedir. Mudie vd. (2002), Aksu vd (2002)'de sunulan karotlarda polen ve spor çalışması yaparak, $7-46 \mathrm{~cm} / 1000$ y1l gibi değerler rapor ederler. Londeix vd. (2009) ise kuzeybatı Marmara için yaklaşık son 4000 yıl için ortalama $40 \mathrm{~cm} / 1000$ yıl hızını önermektedir. Kurt ve Yücesoy (2009) İzmit Körfezi içindeki sismik yansıma kesitlerini kullanarak, 30-160 cm/1000 yıl arasında değişen sedimantasyon hızları önermektedir. Görüldüğü gibi Marmara'nın değişik alanlarında ve tortul derinliğine göre, hızlar aşırı derecede çeşitlilik göstermektedir. $\mathrm{Bu}$ çalışma kapsamında ise, İzmit karotunun (IZC-01) lokasyonuna en yakın alanda, Kurt ve Yücesoy (2009)'un önerdiği 160 $\mathrm{cm} / 1000$ yıllık sedimentasyon hızı kullanılmıştır. Çalışmacılar körfezin içindeki çökel paketini 3 ana sınırla ayırmış ve en üstte bulunan 19 metrelik sediment paketinin (T3) çökelme hızını $160 \mathrm{~cm} /$ yıl olarak belirlemişlerdir. İzmit karotunun (IZC01) $200 \mathrm{~cm}$ 'lik boyu ile bu sedimantasyon hiz1 birlikte değerlendirildiğinde, karotun toplam sedimantasyon yaşının ortalama 1250 yıl olduğu kabul edilmiştir. Karadeniz' de yapılan ve doğrudan sedimantasyon hızına yönelik bilimsel çalışmalar, Marmara'ya oranla oldukça kısıtlıdır. Ross (1970), Karadeniz özelinde, kullandığı karotlardan elde etiği radyokarbon yaş verilerini kullanarak 0-10 $\mathrm{cm}, 10-30 \mathrm{~cm}$ ve $>30 \mathrm{~cm} / 1000$ y1l şeklinde 3 alanlı genelleştirilmiş bir sedimantasyon hızı haritası verir. $\mathrm{Bu}$ haritada kıyı şeridi boyunca hız $30 \mathrm{~cm} / 1000$ ve üzeri hızlarla temsil edilmektedir. Sedimantasyon hızının, doğrudan karotlar içinde tespit edilen jeokronolojik yaşlarla ölçülebileceği diğer çalışmalar ise Guichard vd. (1993); Aksu vd. (2002); Lamy vd. (2006) ve Kwiecien vd. (2008)'dir. Bu çalışmalardan Aksu vd (2002)'de güneybatı Karadeniz kıyılarındaki karot ve radyokarbon yaş verileri doğrultusunda hızların $3.5-18 \mathrm{~cm} / 1000$ yıl arasında temsil edildiği görülür. Diğer çalışmalarda ise, Santori'nin Minoan patlamasıyla ilişkili Z-2 tefra seviyesi anahtar düzeyi olarak kullanılmıştır. Bu patlamanın yaşı 3595 GÖ olarak kabul edilmektedir (Hammer vd. 1987; Friedrich vd. 2006). Guichard vd. (1993)'ün, Samsun ve Sinop açıklarındaki karotlarındaki tortul kalınlıklarından, sedimantasyon hızları 15$30 \mathrm{~cm} / 1000$ yıl olarak ölçülür. Sakarya Deltası'nın açıklarındaki karotların tefra seviyesinin üstündeki tortulların kalınlıkları gözetildiğinde, sedimantasyon hizları Lamy vd. (2006)'de 87$130 \mathrm{~cm} / 1000 \mathrm{y} 1$, Kwiecien vd. (2008)'de ise 69-118 cm/1000 y1l olarak hesaplanmaktadır. $\mathrm{Bu}$ çalışma çerçevesinde kullanılan Hopa ve Sürmene karotlarında, bu anahtar tefra seviyesi gözlenmemektedir. Dolayısıyla, karotların boyu orantısında sedimantasyon hızı, Sürmene için 40 $\mathrm{cm} / 1000$ yıl, Hopa için $30 \mathrm{~cm} / 1000$ yıldan fazla olmak zorundadır. Bununla birlikte Sürmene ve Hopa karotlarının lokasyonlarının Sakarya deltasına benzer şekilde, denizel deltaların üzerinde olduğu gözetilirse, sedimantasyon hızlarının deltalardaki yüksek tortul girdisine paralel, diğer kıyı açı̆̆ı enerjisi düşük alanlardan daha hızlı gerçekleşmiş olması sonucu ortaya çıkar. Doğal olarak, Sakarya nehrinin taşıdığı tortul yük ile Sürmene ve Hopa deltalarını besleyen akarsuların toplam yükü arasındaki farktan dolayı, Lamy vd. (2006) ve Kwiecien vd. (2008)'den hesaplanan maksimum sedimantasyon hızlarından daha yavaş bir hızın olma olasılığı kuvvetle muhtemeldir. Bütün bu veriler değerlendirildiğinde, Sürmene karotu için ortalama $70 \mathrm{~cm} / 1000 \mathrm{y} 1$, Hopa için ise $60 \mathrm{~cm} / 1000 \mathrm{y} 1 \mathrm{l}$ gibi bir sedimentasyon hız1 önermek uygun olabilir. Belirlenen bu ortalama hızlara göre, Sürmene karotunun (SC-01, 150 $\mathrm{cm})$ yaklaşı $2150 \mathrm{y} 1$, Hopa (HC-01, $100 \mathrm{~cm}$ ) karotunun ise 1650 y1l olduğu hesaplanmaktadır (Şekil 3). Belirlenen bu olası yaşlara göre, karotlardaki ağır metal konsantrasyonlarının azalma eğilimine girdiği seviyeler, Sürmene ve Hopa karotlarında birbirine yakın olarak 20-25 $\mathrm{cm}$ derinliğinde ve 330-530 y1l arasında, İzmit karotunda ise $40-45 \mathrm{~cm}$ derinliğinde ve 250 
330 y1l arasında hesaplanmaktadır. Karadeniz karotlarından elde edilen radyometrik yaşlarla, literatürde verilen sedimantasyon hızlarından yola çıkılarak hesaplanan ortalama değerlerin aşırı derecede bir tutarlılık içinde olduğu, İzmit karotu özelinde, Kurt ve Yücesoy (2009)'un önerdiği $160 \mathrm{~cm} / 1000$ yıllık sedimentasyon hızının da, bu çalışmada kullanılan karot lokasyonuna çok yakın bir alanda verildiği gözetilirse, değişimlerin bariz bir şekilde anomali verdiği seviyeleri olas1 Antroposen sinırı olarak yorumlamak mümkündür. Sonuç olarak, radyometrik yaş verileri sedimantasyon hizı hesaplamaları ile birleştirildiğinde, bu sınırın, literatürde Antroposen'nin başlangıcı olarak önerilen 3 ana görüşten, Crutzen ve Stoermer (2000), Crutzen (2002), Davis (2011) ve Fischer-Kowalski vd. (2014) gibi çalışmaların önerdiği ve son 200-500 y1l içinde başlamış olduğunu savunan görüşü destekleyen bir sonuca ulaşıldığg görülmektedir. Elbette ki Antroposen'nin başlangıcı bir süre daha jeoloji arenasında bilimsel olarak tartışılacak ve tartışılmalıdır. Fakat hiç şüphesiz yöntemsel olarak bu çalışmaya benzer çalışmaların sayısının artmas1, veri setini zenginleştirecek ve bu jeolojik fenomenin çözülebilmesine büyük katk1 sağlayacaktır.

\section{KATKI BELIRTME}

Bu çalışma, TÜBİTAK 2009/A destek programı kapsamındaki 1919B011500003 nolu proje tarafından desteklenmiştir. Yazarlar, inceleme yapılan karotların temini için Dokuz Eylül Üniversitesi Deniz Bilimleri Enstitüsü'nden Prof. Dr. Doğan Yaşar'a, makalenin hakemliğini yapan ve bilimsel değerinin artırılması adına katkılarını sunan Dr. Şehnaz Şener ve ismini açıklamayan diğer hakeme teşekkürü borç bilir. Ayrıca Simge Şahin'e makalenin ingilizce bölümlerinin düzenlenmesi, Dilge Sümer'e araştırmaya sağladığı fondan dolayı teşekkürlerimizi sunarız.

\section{EXTENDED SUMMARY}

Human activities are increasing with each passing day and this increase has affected the environment both negatively and positively but more so negatively. These effects are moving beyond ordinary the human race in nature, put forward them into a globally decisive force outside its functioning, and theymake us an actor biologically, chemically and geologically (Crutzen \& Stoermer, 2000; Anderrson et al. 2005; Crossland et al. 2005; Crutzen, 2006).

Due to the fact that these anthropogenic affects are measurable on observed geological rocks, Crutzen \& Stoermer (2000) claimed to leave the geological series Holocene, and should be entered into a new one namely the Anthropocene.

In the scientific literature, the initiation of Anthropocene is represented by 3 main views. The Anthropocene had taken places approximately 3000 to 8000 years ago as a result of early human impacts such as increase of inefficient land use and uncontrolled agricultural activities (Ruddiman, 2003; Certini \& Scalenghe, 2011; Ellis, 2011; Wilkinson et al, 2014). However, others claimed that the initiation should had beeen started between 200 to 500 years ago with the emergence of the observed effects of human race impact into the nature such as industrialization and the use of fossil fuels (Crutzen \& Stoermer, 2000; Crutzen, 2002; Davis, 2011; Fischer-Kowalski et al. 2014). And the last one is; it should be in hand in the mid-20th century with global economic growth and associated environmental change, following the end of World War II (Steffen et al. 2007; Wolfe et al. 2014; Zalasiewicz et al. 2015).

Even if presence of anthropogenic pollution in Turkey and even though this had been investigated, the beginning of this pollution or changing of it in geologic time has not been examined methodologically by going through geological layers in ancient times, except for Evans et al. (1989) in Marmara, Atalar et al. 
(2013) in Aegean Sea. In this paper, we performed lithological, sedimentological, paleontological and geochemical studies in 3 drilling cores from the Izmit Bay (IZC-01) in the Sea of Marmara, Sürmene (SC-01) and Hopa (HC-01) coasts in the Black Sea. Heavy metals concentration on sedimentary rocks and their changes depending on the depth in core samples were examined for the first time to find the presence and/or beginning of the Anthropocene time. 15 samples from each 3 cores, total 45 samples were analyzed for heavy metals (As, Ba, Pb, Cd, Cr, Ni, Ti and $\mathrm{Zn)}$ concentration in part per million (ppm) denominations. According to the obtained results of geochemical analysis, it indicates that the sediment samples in the Gulf of Izmit core have more heavy metal contamination than Sürmene and Hopa core samples.

PLI (Pollution load index) values are calculated by using the results of $A s, B a, P b$, $\mathrm{Cr}, \mathrm{Ni}$, and $\mathrm{Zn}$ elements, stand out 3.225 for the Gulf of Izmit, 2,195 and 1,706 for Sürmene and Hopa in respectively, which solidifies that Gulf of Izmit is the most polluted one, Sürmene is at a lower pollution and Hopa is the lowest polluted area. When we compare the PLI value of Gulf of Izmit in contrast to findings in the literature from other polluted area in the world, a value above on average level of pollution is seen. In addition, EF values indicate a significant enrichment of the $\mathrm{As}, \mathrm{Ni}$ and $\mathrm{Cr}$ and moderate enrichment of $\mathrm{Pb}$ and $\mathrm{Zn}$ elements at Izmit Gulf. In locations Hope and Sürmene; $\mathrm{As}, \mathrm{Ba}$ and $\mathrm{Cr}$ elements showing insufficient enrichment and $\mathrm{Ni}, \mathrm{Pb}$ and $\mathrm{Zn}$ was observed a significant enrichment.

Another remarkable fact is that the presence of gypsum crystals in size ranging between $0.5 \mathrm{~cm}$ and1.5 cm in core samples from Gulf of Izmit at Marmara Sea. In addition, the size of the gypsum crystals can be seen in a coarser size younger stratigraphic level top of the core than the bottom side. It is well known in the literature that the forming of gypsum crystals and their triggering of growth are directly related to air and water pollution (Charola et al. 2007; Török et al. 2007; Gomez-Heras et al. 2008; Marszałek et al. 2014). Considering the size of the gypsum crystals, their stratigraphic positions, and in the light of the data presented in the literature combined with together that the growth of the gypsum crystals in the core Gulf of Izmit have been triggered by an anthropogenic pollution.

Another important observation that trends of heavy metals concentration of elements such as $\mathrm{Pb}, \mathrm{Zn}, \mathrm{Cr}$ and As are going to decrease towards the deepest part of the cores.

Radiocarbon dates obtained from the shells of these reduction levels are mesured in Sürmene $420 \pm 55$ (BP) and Hopa 500 50 (BP). In addition, these common levels that give anomalies of this reduction fixed for each cores and mesured ages of these levels have been compared for each ones by using studies in the literature based on the sedimentation rate from similar areas. Consequently, these stunning levels were found for Izmit core 250 to 330 years at $40-45 \mathrm{~cm}$, Sürmene and Hopa cores close to each other 330 to 530 years at $20-25 \mathrm{~cm}$ from the sediment water interface into the deeper part of the cores. As a result we believe that these calculated geological ages supported the beginning of Anthropocene which has been forming within the time period between 200 to 500 years ago which is presented with a theory of Crutzen and Stoermer (2000), Crutzen (2002); Davis (2011) and FisherKowalski et al. (2014). As a matter of course, the initiation of the Anthropocene is still unclear and should be discussed for a while in the scientific arena of geology. However as no doubt, increasing the number of methodically similar studies will enrich the data set, and will provide a significant contribution to solve this geological phenomenon. 


\section{DEĞINIILEN BELGELER}

Abrahim, G. M. S. ve Parker, R. J., 2008. Assessment of heavy metal enrichment factors and the degree of contamination in marine sediments from Tamaki Estuary, Auckland, New Zealand. Environmental Monitoring and Assessment, 136, 227-238.

Adamo, P., Arienzo, M., Imperato, M., Naimo, D., Nardi, G., ve Stanzione, D., 2005. Distribution and partition of heavy metals in surface and sub-surface sediments of Naples city port. Chemosphere, 61(6), 800-809.

Aksu, A. E., Hiscott, R. N., Kaminski, M. A., Mudie, P. J., Gillespie, H., Abrajano, T. ve Yaşar, D., 2002. Last glacial-Holocene paleoceanography of the Black Sea and Marmara Sea: stable isotopic, foraminiferal and coccolith evidence. Marine Geology, 190(1), 119-149.

Aksu, A. E., Yaşar, D. ve Uslu, O., 1998. Assessment of marine pollution in Izmir Bay: Heavy metal and organic compound concentrations in surficial sediments. Turkish Journal of Engineering and Environmental Sciences, 22(5), 387-416.

Andersson, A. J., Mackenzie, F. T. ve Lerman, A., 2005. Coastal ocean and carbonate systems in the high $\mathrm{CO} 2$ world of the Anthropocene. American Journal of Science, 305(9), 875-918.

Aslan-Yılmaz, A., Okuş, E. ve Övez, S., 2004. Bacteriological indicators of anthropogenic impact prior to and during the recovery of water quality in an extremely polluted estuary, Golden Horn, Turkey. Marine Pollution Bulletin, 49(11), 951-958.

Atalar, M., Kucuksezgin, F., Duman, M., ve Gonul, L. T., 2013. Heavy metal concentrations in surficial and core sediments from Izmir Bay: an assessment of contamination and comparison against sediment quality benchmarks. Bulletin of Environmental Contamination and Toxicology, 91(1), 69-75.

Balkıs, N., Aktan, Y. ve Balkıs, N., 2012. Toxic metal $(\mathrm{Pb}, \mathrm{Cd}$ and $\mathrm{Hg}$ ) levels in the nearshore surface sediments from the European and Anotolian Shores of Bosphorus, Turkey. Marine Pollution Bulletin, 64 (9), 1938-1939.

Bampton, M., 1999. Anthropogenic transformation. In Environmental Geology (pp. 22-27). Springer Netherlands.
Bermejo, J. S., Beltrán, R. ve Ariza, J. G., 2003. Spatial variations of heavy metals contamination in sediments from Odiel river (Southwest Spain). Environment International, 29 (1), 69-77.

Bhuiyan, M. A., Parvez, L., Islam, M. A., Dampare, S. B. ve Suzuki, S., 2010. Heavy metal pollution of coal mine-affected agricultural soils in the northern part of Bangladesh. Journal of Hazardous Materials, 173 (1), 384-392.

Birch, G., Siaka, M. ve Owens, C., 2001. The source of anthropogenic heavy metals in fluvial sediments of a rural catchment: Coxs River, Australia. Water, Air, and Soil Pollution, 126 (1-2), 13-35.

Buat-Menard, P. Ve Chesselet, R., 1979. Variable influence of the atmospheric flux on the trace metal chemistry of oceanic suspended matter. Earth and Planetary Science Letters, 42 (3), 399-411.

Certini, G. ve Scalenghe, R., 2011. Anthropogenic soils are the golden spikes for the Anthropocene. The Holocene, 21, 1269-1274.

Charola, A. E., Pühringer, J. ve Steiger, M., 2007. Gypsum: a review of its role in the deterioration of building materials. Environmental Geology, 52(2), 339-352.

Crossland, C. J., Kremer, H. H., Lindeboom, H., Crossland, J. I. M. ve Le Tissier, M. D., 2005. Coastal fluxes in the Anthropocene: the landocean interactions in the coastal zone project of the International Geosphere-Biosphere Programme. Springer Science \& Business Media, Berlin, $232 \mathrm{~s}$.

Crutzen P. J. ve Stoermer, E. F., 2000. The Anthropocene. Global Change Newsl. 41, 17-18.

Crutzen, P.J., 2002. Geology of mankind. Nature, 415, 23.

Crutzen, P.J., 2006. The "Anthropocene". Ehlers E. Ve Krafft T. (Eds.), Earth System Science in the Anthropocene. Springer Berlin Heidelberg, Heidelberg, 273 s.

Çağatay, M.N., Saltoğlu, T. ve Gedik, A., 1987. Karadeniz'in güncel çökellerinin jeokimyası. Geological Engineering, 30-31, 47-64.

Davis, R.V., 2011. Inventing the present: historical roots of the Anthropocene. Earth Science History, 30, 63-84.

Demirbağ, E., Rangin, C., Le Pichon, X. ve Celal, A.M.C., 2003. Investigation of the tectonics of 
the Main Marmara Fault by means of deep-towed seismic data. Tectonophysics, 361, 1-19.

Eichler, A., Tobler, L., Eyrikh, S., Malygina, N., Papina, T. ve Schwikowski, M., 2014. Ice-core based assessment of historical anthropogenic heavy metal $(\mathrm{Cd}, \mathrm{Cu}, \mathrm{Sb}, \mathrm{Zn})$ emissions in the Soviet Union. Environmental science ve technology, 48(5), 2635-2642.

Ellis, E. C. ve Ramankutty, N., 2008. Putting people in the map: anthropogenic biomes of the world. Frontiers in Ecology and the Environment, 6(8), 439-447.

Ellis, E. C., 2011. Anthropogenic transformation of the terrestrial biosphere. Philosophical Transactions of the Royal Society of London A: Mathematical, Physical and Engineering Sciences, 369 (1938), 1010-1035.

Ergin, M., Bodur, M. N., Yildiz, M., Ediger, D., Ediger, V., Yemeniciog, S. ve Yücesoy, F., 1994. Sedimentation rates in the sea of Marmara: a comparison of results based on organic carbonprimary productivity and $210 \mathrm{~Pb}$ dating. Continental Shelf Research, 14(12), 1371-1387.

Ergin, M., Saydam, C., Baştürk, Ö., Erdem, E. ve Yörük, R., 1991. Heavy metal concentrations in surface sediments from the two coastal inlets (Golden Horn Estuary and Izmit Bay) of the northeastern Sea of Marmara. Chemical Geology, 91(3), 269-285.

Essien, J. P., Antai, S. P. ve Olajire, A.A., 2009. Distribution, seasonal variations and ecotoxicological significance of heavy metals in sediments of cross river estuary mangrove swamp. Water, Air, and Soil Pollution, 197(1-4), 91-105.

Evans, G., Erten, H., Alavi, S. N., Von Gunten, H. R. ve Ergin, M., 1989. Superficial deep-water sediments of the eastern Marmara basin. Geo-marine Letters, 9(1), 27-36.

Fischer-Kowalski, M., Krausmann, F. ve Pallua, I., 2014. A sociometabolic reading of the Anthropocene: Modes of subsistence, population size and human impact on Earth. The Anthropocene Review, 1, 8-33.

Friedrich, W.L., Kromer, B., Friedrich, M., Heinemeier, J., Pfeiffer, T. ve Talamo, S., 2006. Santorini Eruption Radiocarbon Dated to $1627-1600$ B.C. Science, 312, 548.
Galuszka, A., Migaszewski, Z. M. ve Zalasiewicz, J., 2014. Assessing the Anthropocene with geochemical methods. Geological Society, London, Special Publications, 395(1), 221-238.

Gomez-Heras, M., Smith, B. J. ve Viles, H. A., 2008. Laboratory modelling of gypsum crust growth on limestone related to soot pollution and gaseous sulphur: implications of 'cleaner'environments for stone decay. In Lukaszewicz, J.W., Niemcewicz, P. (Editors), 11th International Congress on Deterioration and Conservation of Stone (2 volumes). Wydawnictwo Naukowe Universytetu Mikolaja Kopernika, Torun. pp. 105-112

Gökmen, A., Yıldız, M., Erten, H. N. ve Salihoğlu, İ., 1996. Dating the Sea of Marmara sediments by a uniform mixing model. Journal of Environmental Radioactivity, 33(1), 91-104

Guichard, F., Carey, S., Arthur, M.A., Sigurdsson, H., Arnold, M., 1993. Tephra from the Minoan eruption of Santorini in sediments of the Black Sea, Nature, 363, 610-612.

Güler, C., Kurt, M. A., Alpaslan M. ve Akbulut, C., 2012. Assessment of the impact of anthropogenic activities on the groundwater hydrology and chemistry in Tarsus coastal plain (Mersin, SE Turkey) using fuzzy clustering, multivariate statistics and GIS techniques. Journal of Hydrology, 414, 435-451.

Gürbüz, A. ve Gürer, Ö.F., 2008. Anthropogenic affects on lake sedimentation process: a case study from Lake Sapanca, NW Turkey. Environmental Geology, 56(2), 299-307.

Hakanson, L., 1980. An ecological risk index for aquatic pollution control: a sedimentological approach. Water Research, 14, 975-1001.

Hall, K.J., 2002. Bathymetric compilations of the seas around Israel I: the Caspian and Black seas. Geological Survey of Israel Current Research, 13, 105-108.

Halstead, M. J., Cunninghame, R. G. ve Hunter, K. A., 2000. Wet deposition of trace metals to a remote site in Fiordland, New Zealand. Atmospheric Environment, 34(4), 665-676.

Hammer, C.U., Clausen, H.B., Friedrich, W.L. ve Tauber, H., 1987. The Minoan eruption of Santorini in Greece dated to 1864 BC? Nature, $328,517-519$. 
Huerta-Diaz, M. A., Delgadillo-Hinojosa, F., Hernández-Ayón, M., Segovia-Zavala, J. A., García-Esquivel, Z., López-Zárate, H., SiqueirosValencia. A. ve Galindo-Bect, S., 2008. Diagnosis of trace metal contamination in sediments: the example of Ensenada and El Sauzal, two harbors in Baja California, Mexico. Marine Environmental Research, 66(3), 345-358.

Kahvecioğlu, Ö., Kartal, G., Güven, A. ve Timur, S., 2003. Metallerin çevresel etkileri-I. Metalurji Dergisi, 136, 47-53.

Kaska, Y., Başkale, E., Urhan, R., Katılmış, Y., Gidiş, M., Sarı, F., Sözbilen, D., Canbolat, A.F., Yılmaz, F., Barlas, M., Özdemir, N. ve Özkul, M., 2010. Natural and anthropogenic factors affecting the nest-site selection of Loggerhead Turtles, Caretta caretta, on Dalaman-Sarıgerme beach in Southwest Turkey: (Reptilia: Cheloniidae). Zoology in the Middle East, 50(1), 47-58.

Koreneva, E.V., 1971. Spores and pollen in Mediterranean bottom sediments. In: Funnell, B.M., Riedel, W.R. (Eds.), The Micropaleontology of the Oceans. Cambridge University Press, Cambridge, $828 \mathrm{~s}$.

Kurt, H. ve Yücesoy, E., 2009. Submarine structures in the Gulf of İzmit, based on multichannel seismic reflection and multibeam bathymetry. Marine Geophysical Researches, 30(2), 73-84.

Kwiecien, O., Arz, H.W., Lamy, F., Wulf, S., Bahr, A., Röhl, U. ve Haug, G.H., 2008. Estımated reservorr ages of the Black Sea since the last glacial. Radiocarbon, 50, 99-118.

Lamy, F., Arz, H.W., Bond, G., Bahr, A. ve Pätzold, J., 2006. Multicentennial-scale hydrological changes in the Black Sea and northern Red Sea during the Holocene and the Arctic/North Atlantic Oscillation. Paleoceanography, 21, PA1008.

Londeix, L., Herreyre, Y., Turon, J. L. ve Fletcher, W., 2009. Last Glacial to Holocene hydrology of the Marmara Sea inferred from a dinoflagellate cyst record. Review of Palaeobotany and Palynology, 158(1), 52-71.

Loska, K. ve Wiechuła, D., 2003. Application of principal component analysis for the estimation of source of heavy metal contamination in surface sediments from the Rybnik Reservoir. Chemosphere, 51(8), 723-733.
Marsh, G.P., 1865. Man and nature, physical geography as modified by human action. Charles Scribner, New York, $593 \mathrm{~s}$.

Marszałek, M., Alexandrowicz, Z. ve Rzepa, G., 2014. Composition of weathering crusts on sandstones from natural outcrops and architectonic elements in an urban environment. Environmental Science and Pollution Research, 21(24), 14023-14036.

McHugh, C. M., Gurung, D., Giosan, L., Ryan, W. B., Mart, Y., Sancar, U., Burckle, L. ve Cagatay, M. N., 2008. The last reconnection of the Marmara Sea (Turkey) to the World Ocean: a paleoceanographic and paleoclimatic perspective. Marine Geology, 255(1), 64-82.

MGDS (Marine Geocience Data System), 2016. http:// www.marine-geo.org, 01 April 2016.

Mohiuddin, K. M., Zakir, H. M., Otomo, K., Sharmin, S. ve Shikazono, N., 2010. Geochemical distribution of trace metal pollutants in water and sediments of downstream of an urban river. International Journal of Environmental Science ve Technology, 7(1), 17-28.

Moore, F., Attar, A. ve Rastmanesh, F., 2011. Anthropogenic sources of heavy metals in deposited sediments from runoff and industrial effluents, Shiraz, SW Iran. International Proceedings of Chemical, Biological ve Environmental Engineering, 6, 215-219.

Morillo, J., Usero, J., ve Gracia, I., 2002. Heavy metal fractionation in sediments from the Tinto River (Spain). International Journal of Environmental \& Analytical Chemistry, 82(4), 245-257.

Mudie, P. J., Rochon, A. ve Aksu, A. E., 2002. Pollen stratigraphy of Late Quaternary cores from Marmara Sea: land-sea correlation and paleoclimatic history. Marine Geology, 190(1), 233-260.

Mudie, P. J., Rochon, A., ve Aksu, A. E., 2002. Pollen stratigraphy of Late Quaternary cores from Marmara Sea: land-sea correlation and paleoclimatic history. Marine Geology, 190(1), 233-260.

Omgbu, J.A. ve Kokogbo, M.A., 1993. Determination of $\mathrm{Zn}, \mathrm{Pb}, \mathrm{Cn}$ and $\mathrm{Hg}$ in soils of Ekpan, Nigeria. Environ Int, 19, 611-612. 
Owen, R. B. ve Sandhu, N., 2000. Heavy metal accumulation and anthropogenic impacts on Tolo Harbour, Hong Kong. Marine Pollution Bulletin, 40(2), 174-180.

Palanques, A. ve Diaz, J. I., 1994. Anthropogenic heavy metal pollution in the sediments of the Barcelona continental shelf (Northwestern Mediterranean). Marine Environmental Research, 38(1), 17-31.

Ramsey, C. B., ve Lee, S., 2013. Recent and planned developments of the program OXCAL. Radiocarbon, 55, 720-730.

Rashed, M.N., 2010. Monitoring of contaminated toxic and heavy metals, from mine tailings through age accumulation, in soil and some wild plants at Southeast Egypt. Journal of Hazardous Materials, 178(1), 739-746.

Ray, A.K., Tripathy, S.C., Patra, S. ve Sarma, V.V., 2006. Assessment of Godavari estuarine mangrove ecosystem through trace metal studies. Environment International, 32(2), 219-223.

Reimer PJ, Bard E, Bayliss A, Beck JW, Blackwell PG, Bronk Ramsey C, Buck CE, Cheng H, Edwards RL, Friedrich M, Grootes PM, Guilderson TP, Haflidason H, Hajdas I, Hatté C, Heaton TJ, Hoffmann DL, Hogg AG, Hughen KA, Kaiser KF, Kromer B, Manning SW, Niu M, Reimer RW, Richards DA, Scott EM, Southon JR, Staff RA, Turney CSM, van der Plicht J. 2013. IntCal13 and Marine13 radiocarbon age calibration curves 0-50,000 years cal BP. Radiocarbon 55(4):18691887 .

Riemann, L., Steward, G. F., ve Azam, F., 2000. Dynamics of bacterial community composition and activity during a mesocosm diatom bloom. Applied and Environmental Microbiology, 66(2), 578-587.

Ross, D.A., 1970. Black Sea: Recent Sedimentary History. Science, 170 (3954), 163-165.

Ruddiman, W.F., 2003. The anthropogenic greenhouse era began thousands of years ago. Climatic Change, 61(3), 261-293.

Sağlam, N. ve Cihangir, N., 1995. Ağır metallerin biyolojik süreçlerle biyosorbisyonu çalışmaları. Hacettepe Üniversitesi Eğitim Fakültesi Dergisi, 11(11).

Schiff, K. C. ve Weisberg, S. B., 1999. Iron as a reference element for determining trace metal enrichment in southern California coastal shelf sediments. Marine Environmental Research, 48(2), 161-176.

Skripkin, V. V. ve Kovaliukh, N. N., 1998. Recent developments in the procedures used at the SSCER laboratory for the routine preparation of lithium carbide. Radiocarbon, 40(1), 211-214.

Spencer, K. L., Cundy, A. B., ve Croudace, I. W., 2003. Heavy metal distribution and early-diagenesis in salt marsh sediments from the Medway Estuary, Kent, UK. Estuarine, Coastal and Shelf Science, 57, 43-54,

Stanley, D. J. ve Blanpied, C., 1980. Late Quaternary water exchange between the eastern Mediterranean and the Black Sea. Nature, 285, 537-541.

Steffen, W., Crutzen, P. J. ve McNeill, J. R., 2007. The Anthropocene: are humans now overwhelming the great forces of nature. AMBIO: A Journal of the Human Environment, 36(8), 614-621.

Sutherland, B. R., 2000. Internal wave reflection in uniform shear. Quarterly Journal of the Royal Meteorological Society, 126(570), 3255-3286.

Szefer, P., Kusak, A., Szefer, K., Glasby, G. P., Jankowska, H., Wołowicz, M. ve Ali, A. A. 1998. Evaluation of the anthropogenic influx of metallic pollutants into Puck Bay (southern Baltic). Applied Goechemistry, 13, 293-304.

Şener, Ş., Davraz, A. ve Karagüzel, R., 2013. Evaluating the anthropogenic and geologic impacts on water quality of the Eğirdir Lake, Turkey. Environmental Earth Sciences, 70(6), 2527-2544.

Tomlinson, D. L., Wilson, J. G., Harris, C. R. ve Jeffrey, D. W., 1980. Problems in the assessment of heavy-metal levels in estuaries and the formation of a pollution index. Helgoländer Meeresuntersuchungen, 33(1-4), 566-575.

Török, Á., Siegesmund, S., Müller, C., Hüpers, A., Hoppert, M. ve Weiss, T. 2007. Differences in texture, physical properties and microbiology of weathering crust and host rock: a case study of the porous limestone of Budapest (Hungary). Geological Society, London, Special Publications, 271(1), 261-276.

Turekian, K. K. ve Wedepohl, K. H., 1961. Distribution of the elements in some major units of the earth>s crust. Geological Society of America Bulletin, 72(2), 175-192. 
Valdés, J., Vargas, G., Sifeddine, A., Ortlieb, L., ve Guinez, M., 2005. Distribution and enrichment evaluation of heavy metals in Mejillones Bay $\left(23^{\circ} \mathrm{S}\right)$, Northern Chile: geochemical and statistical approach. Marine Pollution Bulletin, 50(12), 1558-1568.

Van Driessche, A. E. S., García-Ruíz, J. M., Tsukamoto, K., Patiño-Lopez, L. D. ve Satoh, H., 2011. Ultraslow growth rates of giant gypsum crystals. Proceedings of the National Academy of Sciences, 108(38), 15721-15726.

Waters, C. N., Zalasiewicz, J., Summerhayes, C., Barnosky, A. D., Poirier, C., Gałuszka, A., Cearreta, A., Edgeworth, M., Ellis, E.C., Ellis, M., Jeandel, C., Leinfelder, R., McNeill, J.R., Richter, D.D., Steffen, W., Syvitski, J., Vidas, D., Wagreich, M., Williams, M., Zhisheng, A., Grinevald, J., Odada, E., Oreskes, N. ve Wolfe, A.P.,2016. The Anthropocene is functionally and stratigraphically distinct from the Holocene. Science, 351(6269), aad2622,1-10.

Wilkinson, I. P., Poirier, C., Head, M. J., Sayer, C. D. ve Tibby, J., 2014. Microbiotic signatures of the Anthropocene in marginal marine and freshwater palaeoenvironments. Geological Society, London, Special Publications, 395(1), 185-219.

Wolfe, A. P., Hobbs, W. O., Birks, H. H., Briner, J. P., Holmgren, S. U., Ingólfsson, Ó., Kaushal. S.S., Miller, G.H., Pagani, M., Saros, J.E. ve Vinebrooke, R. D., 2013. Stratigraphic expressions of the Holocene-Anthropocene transition revealed in sediments from remote lakes. Earth-Science Reviews, 116, 17-34.
Yang, K., Nam, T., Nam, K. ve Kim, Y. J., 2016. Characteristics of heavy metal contamination by anthropogenic sources in artificial lakes of urban environment. KSCE Journal of Civil Engineering, 20(1), 121-128.

Yaşar, D., Aksu, A. E. ve Uslu, O., 2001. Anthropogenic pollution in Izmit Bay: heavy metal concentrations in surface sediments. Turkish Journal of Engineering and Environmental Sciences, 25(4), 299-313.

Yatkin, S. ve Bayram, A., 2008. Determination of major natural and anthropogenic source profiles for particulate matter and trace elements in Izmir, Turkey. Chemosphere, 71(4), 685-696.

Zalasiewicz, J., Waters, C. N., Williams, M., Barnosky, A. D., Cearreta, A., Crutzen, P., Ellis, E., Ellis, A. M., Fairchild, J.I., Grinevald J., Haff, K.P., Hajdas. I., Leinfelder, R., McNeill, J., Odada, E.O., Poirier, C.,Richter D., Steffen, W., Summerhayes, C., Syvitski, P.M.J., Vidas, D., Wagreich, M., Wing, S.L., Wolfe, S.L.A., Zhisheng. A. ve Oreskes, N., 2015. When did the Anthropocene begin? A mid-twentieth century boundary level is stratigraphically optimal. Quaternary International, 383, 196-203.

Zhang, C., Qiao, Q., Piper, J. D. ve Huang, B., 2011. Assessment of heavy metal pollution from a Fe-smelting plant in urban river sediments using environmental magnetic and geochemical methods. Environmental Pollution, 159(10), 3057-3070. 